\title{
Effect of phase transformation on
} mechanical properties of

\section{$\mathrm{Al}_{16.80} \mathrm{Co}_{20.74} \mathrm{Cr}_{20.49} \mathrm{Fe}_{21.28} \mathrm{Ni}_{20.70}$ high entropy alloy coatings processed by laser cladding}

\author{
Xingru Wei ${ }^{\mathrm{a}, \mathrm{b}}$, Peilei Zhang ${ }^{\mathrm{a}, \mathrm{b}, \mathrm{c}, *}$, Zhishui Yu${ }^{\mathrm{a}, \mathrm{b}, *}$, Hua Yan ${ }^{\mathrm{a}, \mathrm{b}}$, Di Wu ${ }^{\mathrm{a}, \mathrm{b}}$, Haichuan Shi ${ }^{\mathrm{a}, \mathrm{b}}$, \\ Jieshi Chen ${ }^{\mathrm{a}, \mathrm{b}}$, Qinghua Lu ${ }^{\mathrm{a}, \mathrm{b}}$, Yingtao Tian ${ }^{\mathrm{d}}$, Songyun Ma ${ }^{\mathrm{e}}$, Weisheng Lei ${ }^{\mathrm{a}, \mathrm{b}}$ \\ a. School of Materials Engineering, Shanghai University of Engineering Science, Shanghai \\ 201620, China \\ b. Shanghai Collaborative Innovation Center of Laser of Manufacturing Technology, Shanghai \\ 201620, China \\ ${ }^{c}$ Fraunhofer Institute for Laser Technology ILT, Aachen 52074, Germany \\ ${ }^{d}$ Department of Engineering, Lancaster University, Lancaster LA1 4YW, United Kingdom \\ ${ }^{\mathrm{e}}$ Institute of General Mechanics, RWTH Aachen University, Aachen 52062, Germany
}

*Corresponding author. E-mail address: peilei@ sues.edu.cn (Peilei Zhang); yu_zhishui@163.com ( Zhishui Yu )

\begin{abstract}
:
Eight $\mathrm{Al}_{16.80} \mathrm{Co}_{20.74} \mathrm{Cr}_{20.49} \mathrm{Fe}_{21.28} \mathrm{Ni}_{20.70}$ high entropy alloy (HEA) coatings were fabricated by laser cladding with different laser scanning speed. The mechanical properties caused by phase transformation and microstructure evolution of $\mathrm{Al}_{16.80} \mathrm{Co}_{20.74} \mathrm{Cr}_{20.49} \mathrm{Fe}_{21.28} \mathrm{Ni}_{20.70}$ HEA coatings were investigated. The experimental results showed that the volume fraction of the FCC phase and the BCC phase in each coating were different depending on laser scanning speed. High laser scanning speed will increase the number of $\mathrm{BCC}$ phase. $\mathrm{BCC}$ phase was composed of alternate A2 and B2 structure formed by spinodal decomposition. All coatings exhibited a polycrystalline structure composed of uniform equiaxed grains. The grain size of equiaxed grains reduced from $276 \mu \mathrm{m}$ to $42 \mu \mathrm{m}$ with increased laser scanning speed. The phase-mechanical properties connection at nano-scale were established by nano-hardness mapping and elastic modulus mapping. Furthermore, the micromechanical properties of individual FCC phase and BCC phase were studied by analyze nanoindentation data statistically. The BCC phases were found to have a
\end{abstract}


higher nano-hardness and elastic modulus than the FCC phases. Therefore, the increment of the BCC phase could significantly enhance the strength and wear resistance of coatings. The optimum wear resistance was obtained in V17, owning a higher volume fraction of $\mathrm{BCC}(>90 \%)$ and finer grains $(75 \mu \mathrm{m})$. In addition, the strengthening mechanism has been discussed. Grain boundary strengthening makes a great contribution to the excellent performance of coatings.

KEYWORDS: high entropy alloys; laser cladding; Nanoindentation; Mechanical properties 


\section{Introduction}

High-entropy alloys (HEAs) has received widespread attention since it was first proposed by Yen et al. in 2004 [1]. It was defined as an alloy that included five or more elements with an equimolar or near equimolar ratio, and the content of each element was between $5 \%$ and $35 \%$ [2]. For phase composition, the presence of the high entropy effect and the sluggish diffusion effect promote the formation of single-phase solid solution and nano-sized precipitates rather than brittle phases or other intermetallic compounds in traditional metallurgical theory [3-5]. Numerous studies have implied that HEAs often have excellent mechanical, physical, and chemical properties, such as high-temperature wear resistance [6], high strength and ductility [7] and excellent corrosion resistance [8].

Al-Co-Cr-Fe-Ni system high-entropy alloy system has been mostly studied due to excellent comprehensive property, low cost and huge potential in future applications. The phases usually formed in this system include disordered solid solution FCC phase, disordered solid solution BCC phase (A2) and ordered solid solution BCC phase (B2) [9-14]. According to previous research reports, the mechanical properties of Al-Co-Cr-Fe-Ni HEAs were found strongly depend on the volume fraction and morphology of FCC, BCC and B2 phase. Zhang et al. proposed that the strength of HEAs was related to A2/B2 morphology, $\mathrm{AlCoCrFe}{ }_{2.5} \mathrm{Ni}$ coating with B2 structure made by A2 matrix and B2 precipitates showed higher strength and better wear resistance than that with $\mathrm{B} 2$ matrix and A2 precipitates [15]. The volume fraction of the constituent phases of the $\mathrm{Al}_{\mathrm{x}} \mathrm{CoCrFeNi} \mathrm{HEAs}$ were measured, the deformation mechanism causing the difference in mechanical properties varied according to the volume fraction of $\mathrm{BCC}$. [13]. Furthermore, $\mathrm{Al}_{1.8}$ alloy and $\mathrm{Al}_{2.0}$ alloy with smaller feature size of the spinodal structure exhibited increased hardness compared with $\mathrm{Al}_{1.2}$ alloy and $\mathrm{Al}_{1.5}$ alloy [14]. Therefore, the phase and microstructure are desired to be adjusted to obtain alloys with outstanding comprehensive properties. Zhang et al. added $\mathrm{Cr}$ element (a BCC stabilizer) to single FCC-structured $\mathrm{Al}_{7} \mathrm{Co}_{24} \mathrm{Cr}_{21} \mathrm{Fe}_{24} \mathrm{Ni}_{24}$ to formed $\mathrm{BCC}$ phase, $\left(\mathrm{Al}_{7} \mathrm{Co}_{24} \mathrm{Cr}_{21} \mathrm{Fe}_{24} \mathrm{Ni}_{24}\right)_{74} \mathrm{Cr}_{26}$ alloy 
displyed the best performance, having high yield strength (1649 MPa) and fracture strength (2830 MPa) and good compressive plastic strain of $24.9 \%$ [16]. By adjusting molar ratios of $\mathrm{Al}$ : $\mathrm{Co}$ of $\mathrm{Al}_{\mathrm{x}} \mathrm{CrCo}_{2-\mathrm{x}} \mathrm{FeNi} \mathrm{HEA}$, the phase switched from $\mathrm{FCC}+\sigma+$ disordered $\mathrm{BCC}+$ ordered $\mathrm{BCC}$ structures to $\sigma+$ disordered $\mathrm{BCC}+$ ordered $\mathrm{BCC}$ structures, and then to disordered BCC + ordered BCC structures, and then $\mathrm{Al}_{1.6} \mathrm{CrCo}_{0.4} \mathrm{FeNi}$ alloy with high wear resistance and $\mathrm{Al}_{1.4} \mathrm{CrCo}_{0.6} \mathrm{FeNi}$ alloy with combinations of strength and ductility were manufactured respectively[17]. Qin et al. added Co element to the AlCoCrFeNi, it was found that the addition of Co element increased the volume fraction of the FCC phase having more slip directions and thus improved the plasticity of $\mathrm{AlCoCrFeNi}$ [18]. In addition to adding constituent elements of $\mathrm{AlCoCrFeNi}$ alloy, such as $\mathrm{Co}$ and $\mathrm{Cr}$ mentioned above. It can also add new elements to the base $\mathrm{AlCoCrFeNi}$ alloy to adjust the phase and microstructure. Liu et al. [19] added Si to AlCoCrFeNi, six AlCoCrFeNiSix laser cladding coatings were synthesized, $\mathrm{x}=0,0.1,0.2,0.3,0.4$ and 0.5 ( $\mathrm{x}$ : molar ratio), the addition of $\mathrm{Si}$ atoms affects the microstructure of the coating and causes the dislocation density to increase. They found that the microhardness and dislocations density increased with Si content linearly. Liu et al. [20] also added Ti element to AlCoCrFeNi high-entropy alloy. The in-situ TiC particles generated in the coating have high stability at elevated temperatures, so that AlCoCrFeNiTi0.8 HEA coatings still have good wear resistance at high temperatures of $1200^{\circ} \mathrm{C}$. The above researches are all adding the alloying element into the base alloy to change the evolution of phase and microstructure. However, there is another way to modify the phase and microstructure, that is, to change the solidification behavior by changing the process parameters. Laser cladding is known as a typical non-equilibrium process because of its rapid heating and cooling rates, which will lead to a significant difference in solidification behavior $[21,22]$. And it has been determined that laser cladding coating can effectively improve the performance of metal substrates [23]. Therefore, laser cladding method was chosen to prepare high-entropy alloy coatings in this paper. In the current work, eight coatings with different volume fractions and morphologies of FCC and BCC phase were manufactured by the laser cladding. And the mechanical properties of the different 
phases and the influence of the phase transformation on the mechanical properties of coatings were systematically investigated.

\section{Experimental procedures}

\subsection{Preparation of the coatings}

The $\mathrm{Al}_{16.80} \mathrm{Co}_{20.74} \mathrm{Cr}_{20.49} \mathrm{Fe}_{21.28} \mathrm{Ni}_{20.70}$ HEA coatings were prepared by laser cladding. Commercial HEA powder containing $16.8 \%$ Al, $20.74 \%$ Co, 20.49\%Cr, $21.28 \% \mathrm{Fe}$ and $20.70 \% \mathrm{Ni}$ (at. \%) with high purity (>99.99\%) were used as raw materials, and the particle sizes of the powders were in the range of $15-53 \mu \mathrm{m}$. The HEA powders were preset onto the surface of a Q235 steel substrate with dimensions of $50 \mathrm{~mm} \times 50 \mathrm{~mm} \times 10 \mathrm{~mm}$, and the thickness of the powder layer was $1 \mathrm{~mm}$. Before presetting powder, the surface of each substrate was mechanically polished and cleaned with alcohol to remove all oil and impurities.

Laser cladding was carried out by IPG YLS-5000 fiber system with a protective gas system. Eight HEA laser cladding coatings were prepared in an argon atmosphere with a flow rate of $15 \mathrm{~L} / \mathrm{min}$. The laser scanning speed was $7 \mathrm{~mm} / \mathrm{s}, 9 \mathrm{~mm} / \mathrm{s}, 11 \mathrm{~mm} / \mathrm{s}$, $13 \mathrm{~mm} / \mathrm{s}, 15 \mathrm{~mm} / \mathrm{s}, 17 \mathrm{~mm} / \mathrm{s}, 19 \mathrm{~mm} / \mathrm{s}$ and $21 \mathrm{~mm} / \mathrm{s}$ for eight HEA coatings, thus, named as V7, V9, V11, V13, V15, V17, V19 and V21 in turn. The laser power was selected as $3000 \mathrm{~W}$. The laser cladding parameters and the chemical composition of the HEA powders were shown in Table 1.

Table 1 The processing parameters of laser cladding.

\begin{tabular}{|c|c|c|c|c|c|c|c|c|}
\hline \multirow{2}{*}{ Coating } & \multicolumn{5}{|c|}{ Powder composition(at $\%$ ) } & \multirow{2}{*}{$\begin{array}{c}\text { Laser } \\
\text { power } \\
(\mathrm{W})\end{array}$} & \multirow{2}{*}{$\begin{array}{c}\text { Laser } \\
\text { Scanning } \\
\text { Speed } \\
(\mathrm{mm} / \mathrm{s})\end{array}$} & \multirow{2}{*}{$\begin{array}{c}\text { Thickness } \\
(\mathrm{mm})\end{array}$} \\
\hline & $\mathrm{Al}$ & Co & $\mathrm{Cr}$ & $\mathrm{Fe}$ & $\mathrm{Ni}$ & & & \\
\hline V7 & \multirow{8}{*}{16.80} & \multirow{8}{*}{20.74} & \multirow{8}{*}{20.49} & \multirow{8}{*}{21.28} & \multirow{8}{*}{20.70} & 3000 & 7 & 1 \\
\hline V9 & & & & & & 3000 & 9 & 1 \\
\hline V11 & & & & & & 3000 & 11 & 1 \\
\hline V13 & & & & & & 3000 & 13 & 1 \\
\hline V15 & & & & & & 3000 & 15 & 1 \\
\hline V17 & & & & & & 3000 & 17 & 1 \\
\hline V19 & & & & & & 3000 & 19 & 1 \\
\hline $\mathrm{V} 21$ & & & & & & 3000 & 21 & 1 \\
\hline
\end{tabular}




\subsection{Characterization of the coatings}

X-ray diffractometry (XRD) (D/max-RB, Rigaku Corp, Japan) with $\mathrm{Cu} \mathrm{K} \alpha$ irradiation $(\lambda=0.154060 \mathrm{~nm})$ at a scanning speed of $4 \%$ min was used to identify the phases of the coatings. The cross-section of the coating was ground, polished, cleaned, and then etched to observe the microstructure. The microstructure of the coatings was observed by optical microscopy (OM, VHX-5000) and scanning electron microscopy (SEM, TESCAN VEGA 3) and transition electron microscope (TEM, FEI TECNAI G2 S-TWIN F20) with an EDS detector and high-resolution camera. TEM samples are prepared by the focused ion beam (FIB) technique (FIB, FEI Helios 600).

The middle area of the coating cross-section, an area of $72 \times 72 \mu \mathrm{m}$, was pressed into the indenter at the maximum load of $10 \mathrm{mN}$ using the nanoindentation method. Berkovich indenter with a tip radius of $100 \mathrm{~nm}$ was used. The holding time under peak load was 10 s. 100 indentations were made on each coating. Keysight Nano Indenter G200 was employed in the current study to perform the nanoindentation test. The distance between the two indentations should be 20-30 times the indentation depth. To ensure the accuracy of the measured value, the distance between the indentations was set to $8 \mu \mathrm{m}$, forming a $10 \times 10$ indentation matrix (100 indentations), as shown in Fig. 1.

The friction and wear properties of the coatings were tested by the MFT-5000 multifunctional friction and wear tester (USA, RETC) with the test parameters: the load $40 \mathrm{~N}$, the friction and wear radius $3 \mathrm{~mm}$, the rotation velocity $100 \mathrm{r} / \mathrm{min}$, the friction time $60 \mathrm{~min}$ and the test temperature RT (room temperature) and $800{ }^{\circ} \mathrm{C}$ respectively.
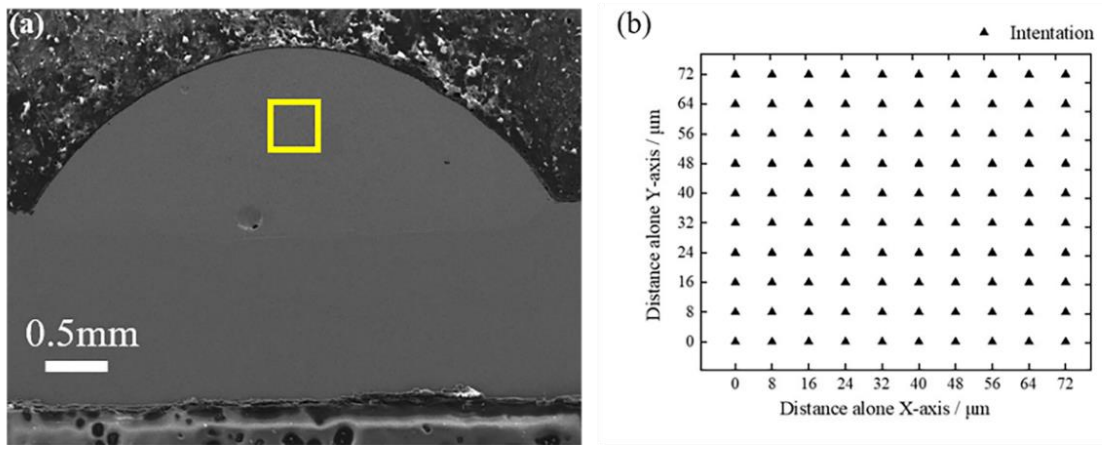
Fig. 1. Schematic diagram of $10 \times 10$ matrix indentations.

\section{Results}

\subsection{Phases analysis}

The XRD patterns of raw powder and eight $\mathrm{Al}_{16.80} \mathrm{Co}_{20.74} \mathrm{Cr}_{20.49} \mathrm{Fe}_{21.28} \mathrm{Ni}_{20.70} \mathrm{HEA}$ coatings processed by different laser scanning speed were shown in Fig. 2(a). Two solid solution phases, face-centered cubic (FCC) solid solution and body-centered cubic (BCC) solid solution were identified from all XRD patterns. When the laser scanning speed was not more than $9 \mathrm{~mm} / \mathrm{s}$ (i.e. V7 and V9), the relative intensity of the FCC reflection peak was much stronger than the intensity of the BCC reflection peak. However, as the laser scanning speed increased, the relative intensity of the FCC diffraction peak gradually decreased, and it almost vanished in V21. When the laser scanning speed was larger than $11 \mathrm{~mm} / \mathrm{s}$, the XRD patterns began to exhibit a strong BCC diffraction peak and a weaker FCC diffraction peak. The intensity evolution of the corresponding peaks of the FCC phase and BCC is related to the volume fraction of these two phases, which will be discussed below. Noticeably, a weak diffraction peak near 30 degrees $2 \theta$ angle appeared in all coatings and raw powder, which corresponded to ordered BCC structure (B2 superstructure). It indicated that the BCC structure in the coatings may consist of disordered BCC phases (A2) and ordered BCC phases (B2) or single ordered BCC phases (B2) [14]. The following research will give a detailed introduction.

The diffraction patterns between 42 and 46 degrees were shown in Fig. 2(b).

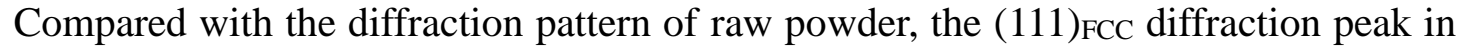
coatings moved to a lower $2 \theta$ angle. The possible reason was that more elements entering the basic close-packed FCC structure, causing the lattice to expand [24]. In V7-V13, the $(110)_{\mathrm{BCC}}$ diffraction peak of the coatings moved to a higher $2 \theta$ angle than the raw powder. Moreover, the shift angle of $(110)_{\mathrm{BCC}}$ diffraction peak increases as the scanning speed increases, and the shift angle in V13 reaches the maximum value, which is $0.073^{\circ}$ higher than the raw powder, as shown in Fig. 3. In V15 and V19, the shift angle of the (110) $)_{\text {BCC }}$ diffraction peak is significantly smaller than that of V13, 


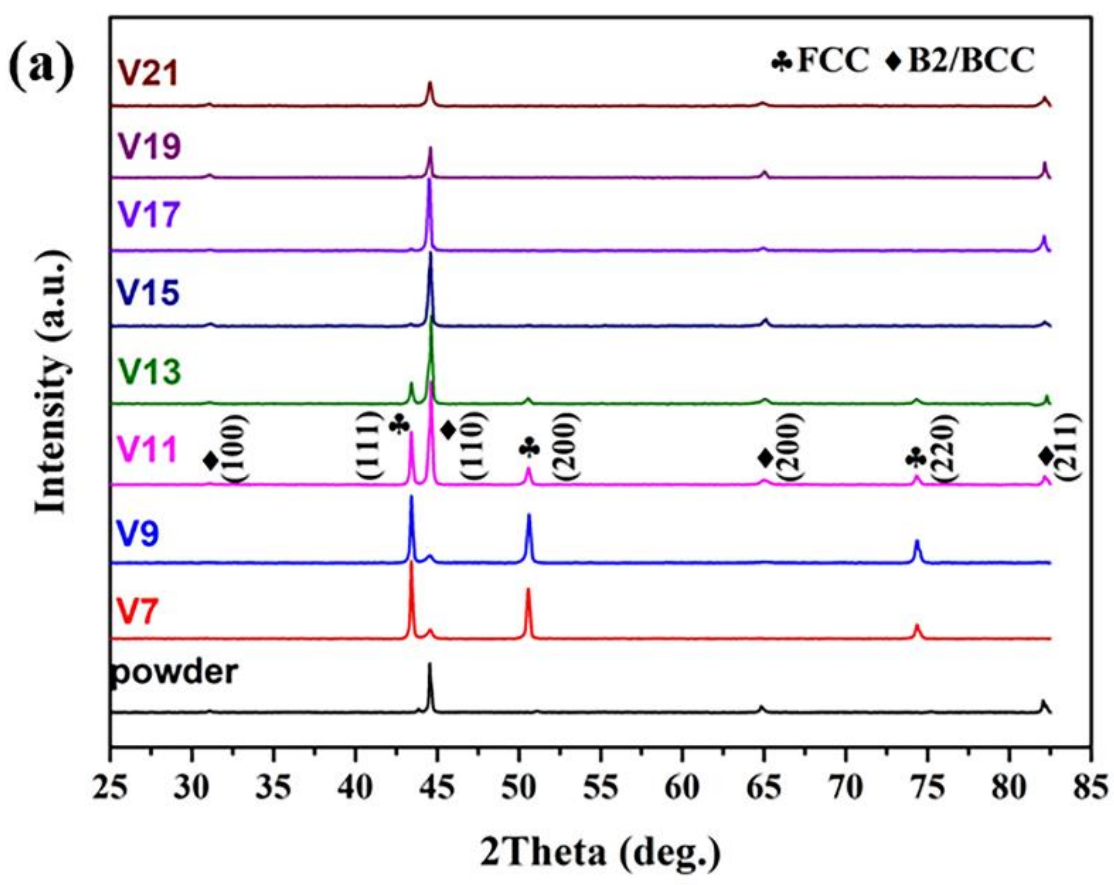




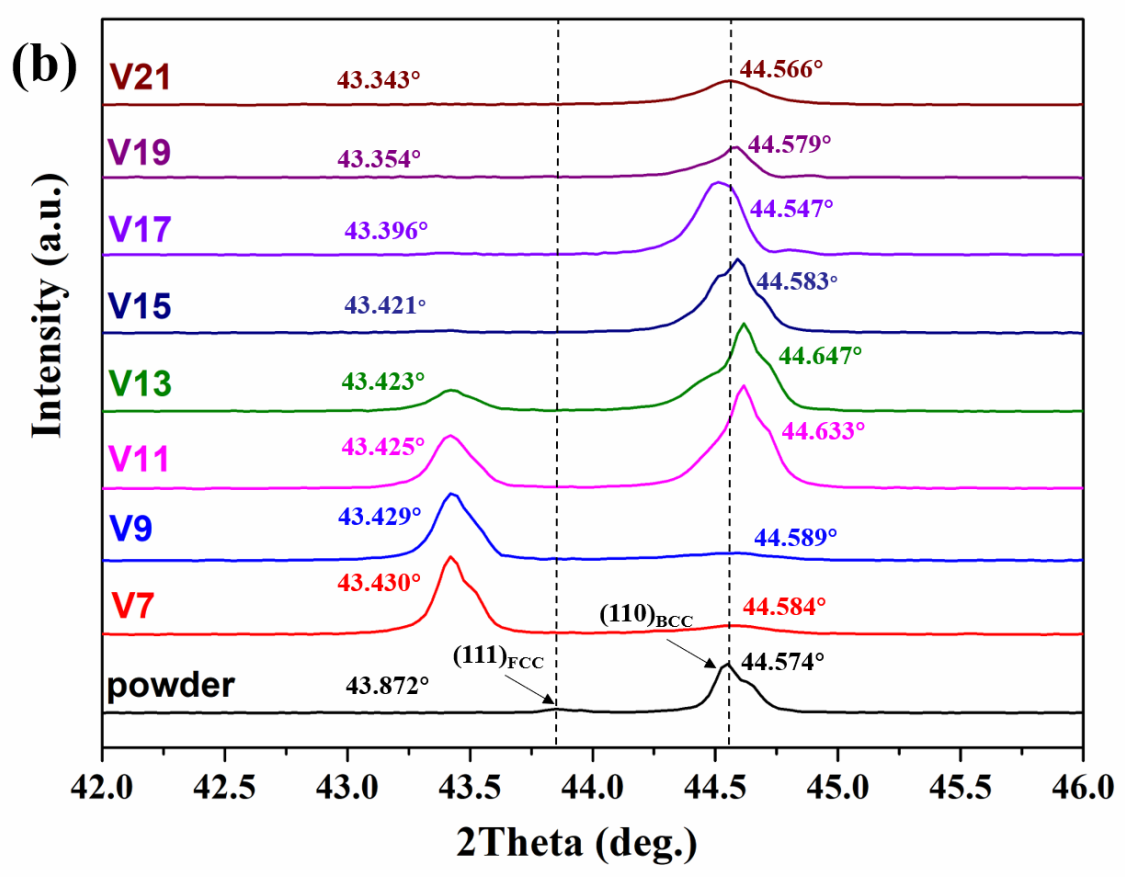

Fig. 2. XRD analyses of $\mathrm{Al}_{16.80} \mathrm{Co}_{20.74} \mathrm{Cr}_{20.49} \mathrm{Fe}_{21.28} \mathrm{Ni}_{20.70} \mathrm{HEA}$ coatings with different laser scanning speed: (a) The XRD patterns of the V7-V21 and powder; (b) The diffraction patterns between 42 and 46 degrees.

\subsection{Microstructural evolution}

Fig. 4 showed the microstructure of V7, V9, V11, V13, V15, V17, V19 and V21. All coatings exhibited polycrystalline structures composed of equiaxed grains [26]. Two precipitation phases, white nanoprecipitates located in the interior and grain boundaries of the equiaxed matrix grains and Widmanstätten side plate originating from grain boundaries, were formed in the V7 and V9 (see Fig .4(a) and (b)). Then, after the laser scanning speed increased to more than $9 \mathrm{~mm} / \mathrm{s}$, there were only the white nanoprecipitates formed in V11-V21. The Widmanstätten side plate structures found in V7 and V9 were FCC phases, which have also been reported in other literature [14,27]. Moreover, Widmanstätten side plates of FCC structure in V9 were finer than V7. It can be seen that the laser scanning speed showed a significant effect on the microstructure. The equiaxed grains size of all coatings were shown in Fig. 5. They were reduced from $276 \mu \mathrm{m}$ to $42 \mu \mathrm{m}$, indicating that increased laser scanning speed had a positive effect on grain refinement when its values varied in the range of $7 \mathrm{~mm} / \mathrm{s}-21 \mathrm{~mm} / \mathrm{s}$. Optical micrographs from the middle parts of the V7, V13, V17 and 
V21 were shown in Fig. 6, V21 with the maximum laser scanning speed exhibited the most refined grains.
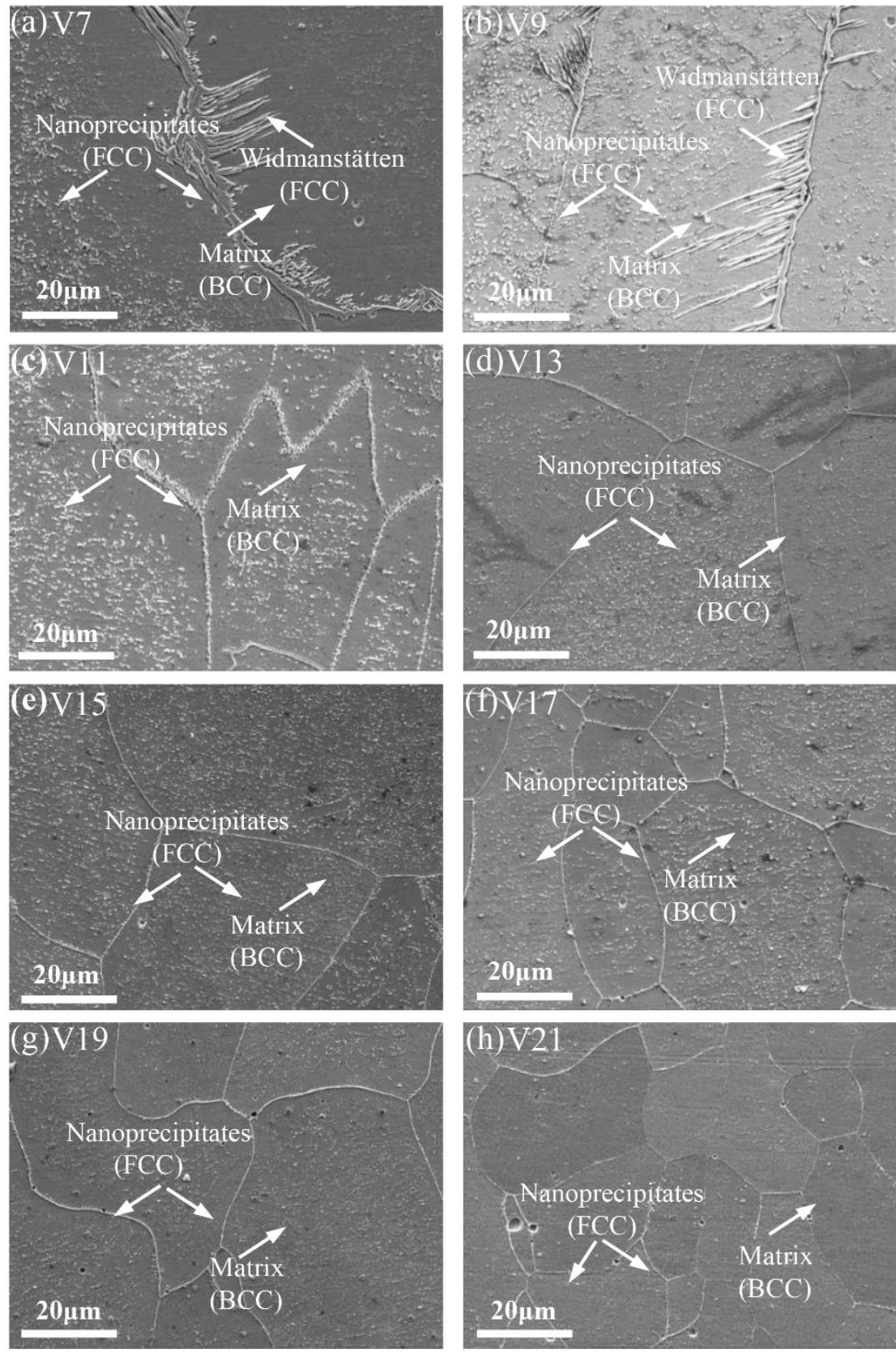

Fig. 4. SEM micrographs of $\mathrm{Al}_{16.80} \mathrm{Co}_{20.74} \mathrm{Cr}_{20.49} \mathrm{Fe}_{21.28} \mathrm{Ni}_{20.70} \mathrm{HEA}$ coatings with different laser scanning speed: (a) and (b) are V7 and V9 with nanoprecipitates and Widmanstätten side plate; (c)-(h) are V11-V21 with nanoprecipitates only. 


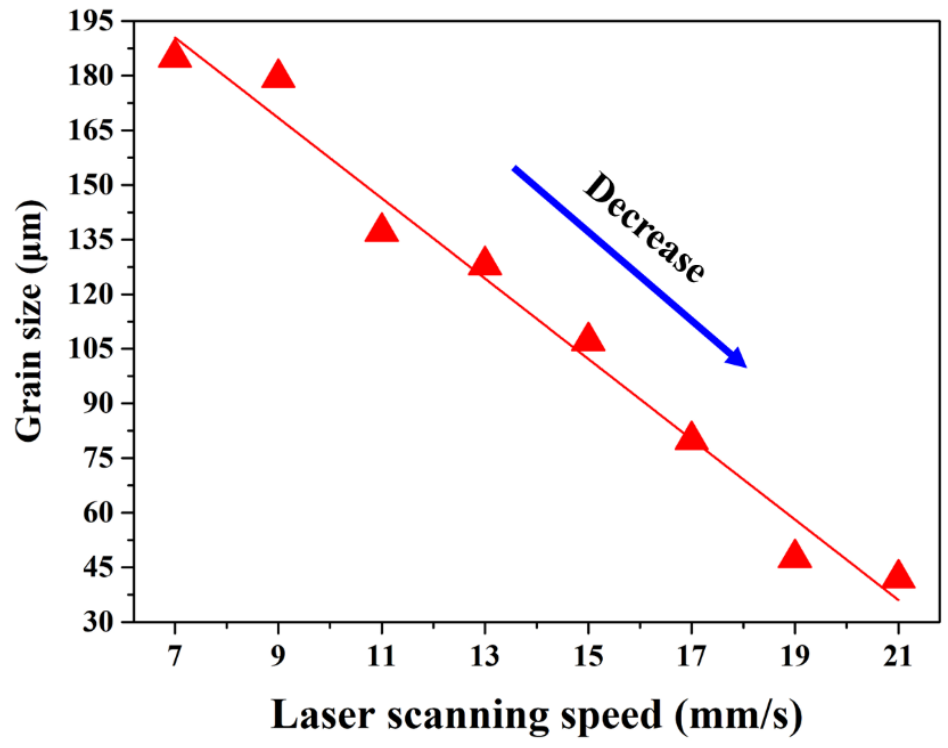

Fig. 5. The equiaxed grain size of $\mathrm{Al}_{16.80} \mathrm{Co}_{20.74} \mathrm{Cr}_{20.49} \mathrm{Fe}_{21.28} \mathrm{Ni}_{20.70} \mathrm{HEA}$ coatings at different laser scanning speed.

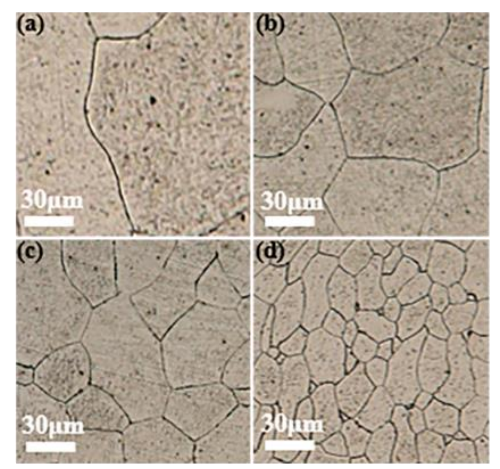

Fig. 6. OM micrographs of middle parts of coatings: (a) V7, (b) V13, (c) V17 and (d) V21.

In order to further reveal the microstructure of the coatings in detail, high-magnification secondary electron images of V7, V13 and V17 were shown in Fig. 7. It showed that the equiaxed matrix grains consisted of nano-scale two alternating bright and dark phases, formed by spinodal decomposition [13, 28-30]. And V7 showed a finer decomposition than V13 and V17, this may be attributed to sufficient solidification time in V7. For further identification, V17 was analyzed by TEM. The SADPs analysis for Region A, C, and D of the equiaxed matrix grains demonstrated that it had a B2 superlattice structure, as shown in Fig. 8. Fig. 9 showed a TEM 

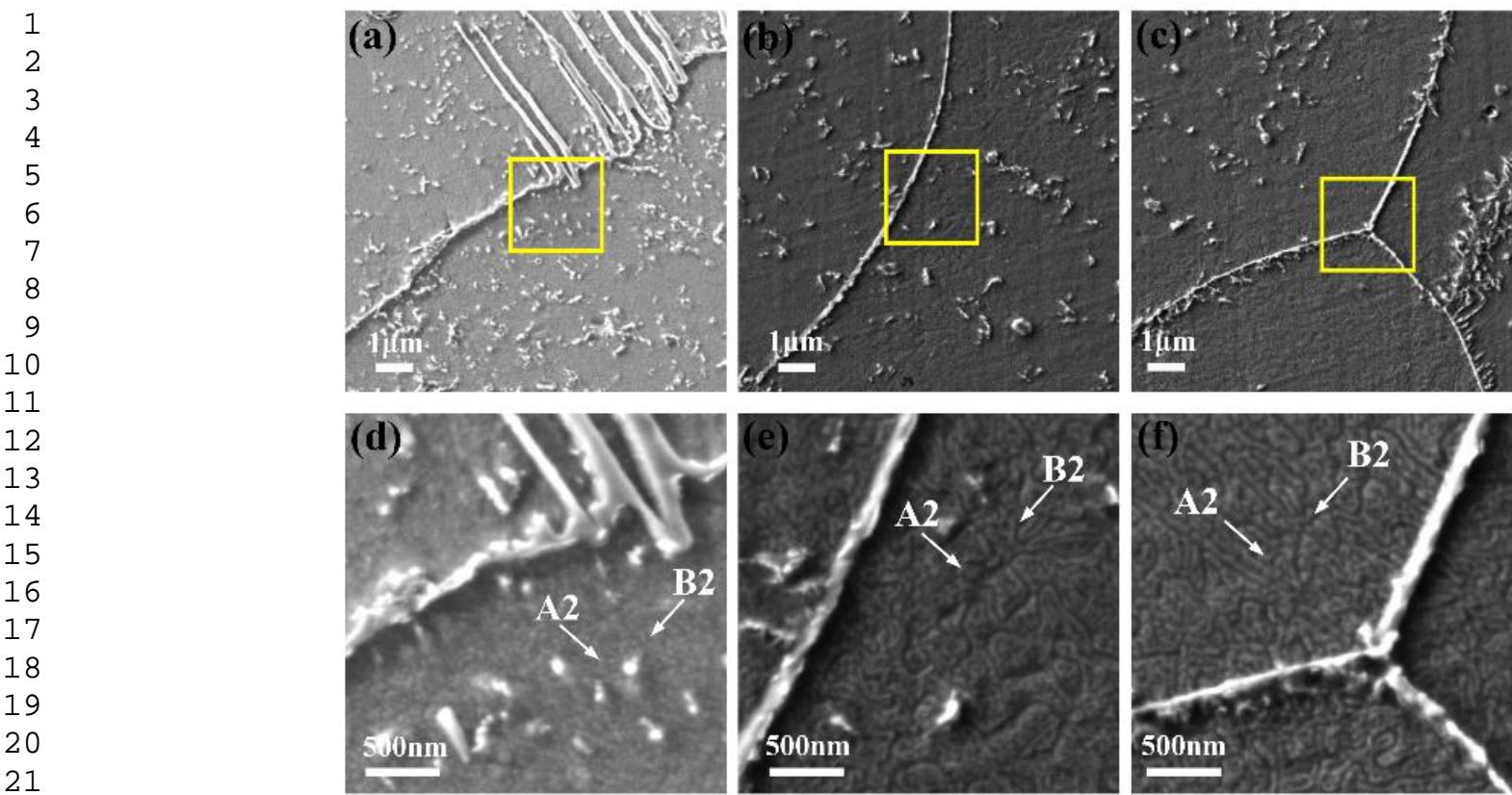

Fig. 7. (a), (b) and (c): High magnification scanning electron micrograph of V7, V13 and V17, respectively; (d), (e)and (f): enlarged view of yellow box in Fig. 7(a), (b) and (c), respectively.

Table 2 TEM-EDS results of V17 (at\%).

\begin{tabular}{lllllll}
\hline Point & Crystal structure & Al & Co & Cr & Fe & Ni \\
\hline E & BCC, matrix & 15.1 & 13.96 & 16.91 & 41.07 & 12.94 \\
F & FCC, nanoprecipitates & 0.3 & 5.51 & 70.1 & 21.92 & 2.14 \\
G & BCC, matrix & 15.32 & 14.74 & 19.02 & 40.44 & 10.45 \\
H & BCC, matrix & 14.66 & 14.83 & 19.87 & 39.89 & 10.72 \\
\hline
\end{tabular}



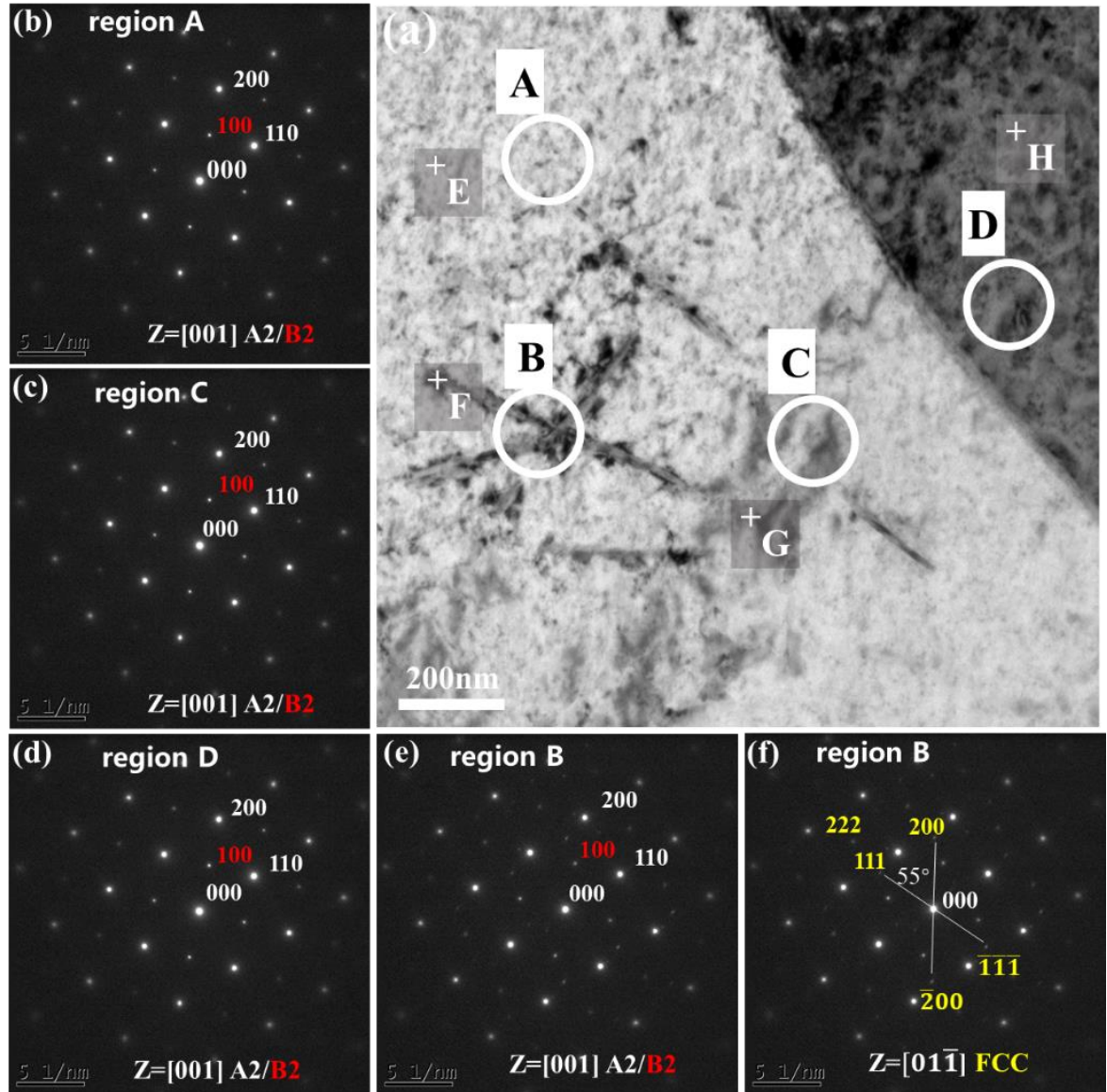

Fig. 8. SADPs of the matrix phase and nanoprecipitates phase in V17: (a) The TEM morphology of V17 near the grain boundary (Bright field image); (b), (c), (d), (e) and (f) are $\mathrm{SADPs}$ of region $\mathrm{A}$, region $\mathrm{B}$, region $\mathrm{C}$ and region $\mathrm{D}$, respectively.
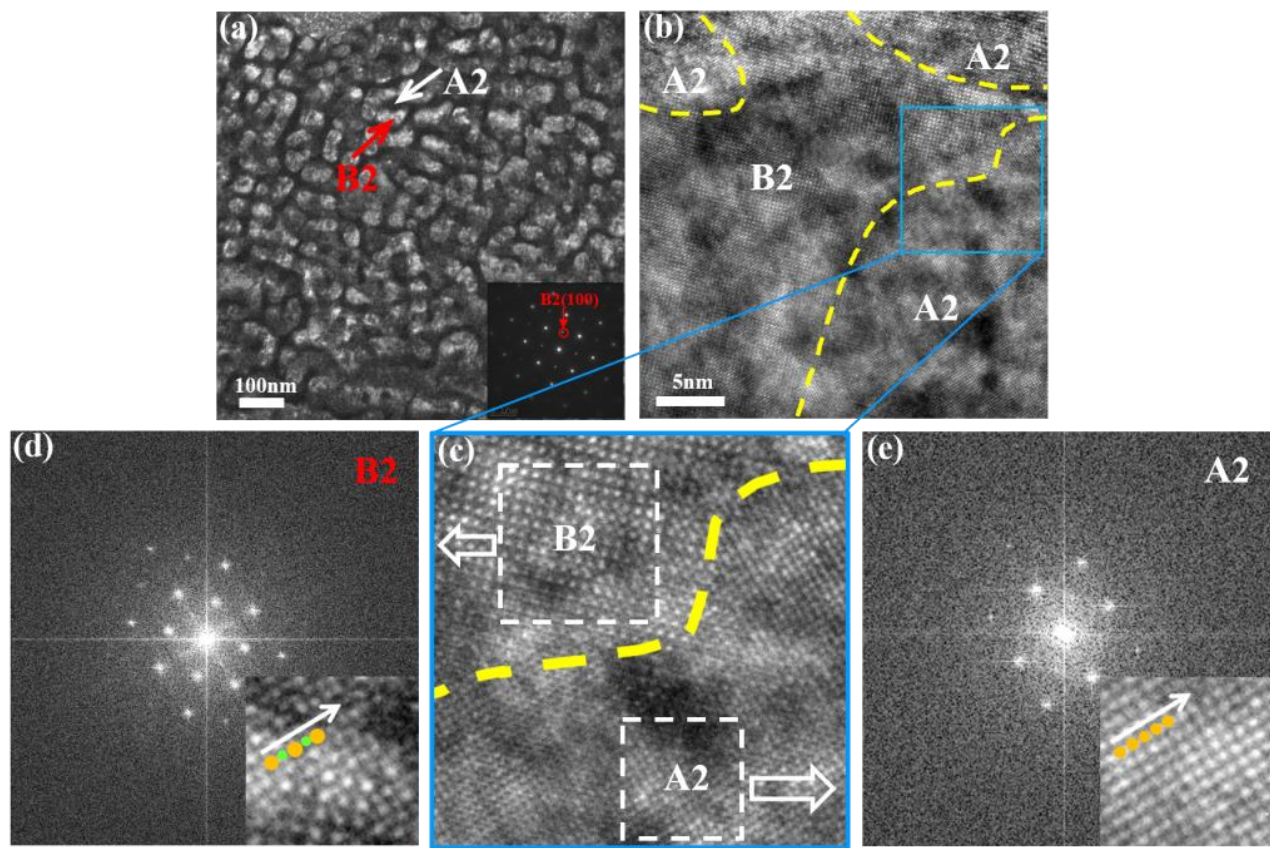
Fig. 9. HRTEM image of the matrix phase of V17: (a): Darkfield image taken from the $(100)_{\mathrm{B} 2}$ reflection marked by a red circle in the SADP (inset); (b): HRTEM image along the <001> direction showing the interface (yellow dashed line) between A2 and B2; (c): Enlarged image of the blue box in Fig.9(b); (d) and (e): FFT patterns from Fig.

$$
\text { 9(c). }
$$

To further identify nanoprecipitates observed in Fig. 4 and Fig. 7. The selected area electron diffraction at the region included nanoprecipitates were performed, and this region was marked as $\mathrm{B}$ in Fig. 8(a). In the SADP of Region B, two sets of patterns were found, and then they were calibrated separately. The results were shown in Fig.8(e) and (f), they were FCC structure and B2 superlattice lattice structure respectively [32]. It also learned that the crystallographic-orientation relationship of the two structures was $(110)_{B 2} \|(1 \overline{1} \overline{1})_{F C C}$ and $[001]_{B 2} \|[01 \overline{1}]_{F C C}$. Region B contains nanoprecipitates and matrix phase (equiaxed matrix grains). The matrix phase is a B2 superlattice lattice structure, therefore, the calibrated FCC structure corresponds to the nanoprecipitates phase. The chemical composition test results of E, F, G, and $\mathrm{H}$ in Fig. 8 were shown in Table 2. Fe and $\mathrm{Cr}$ segregation was found to exist in the nanoprecipitate according to TEM-EDS results of $F$ in Table 2. Therefore, the nanoprecipitates were Cr-rich FCC precipitate phases.

\subsection{Nanoindentation}

The nano-hardness contour map of V7, V13 and V17 were shown in Fig. 10 (a1), (b1), (c1), which drawn using Origin Pro 9.1 software. A lot of blue areas appeared in the nano-hardness contour map of $\mathrm{V7}$, of which the nano-hardness value was below 3.6GPa. The average nano-hardness value of $\mathrm{V} 7$ was $5.4 \mathrm{GPa}$, and the average nano-hardness value of V13 was 6.6GPa. Compared with V7, the average hardness value of V13 increased significantly with the increase of laser scanning speed, and the hardness value increased by $1.2 \mathrm{GPa}$. V17 and V13 have a similar nano-hardness 


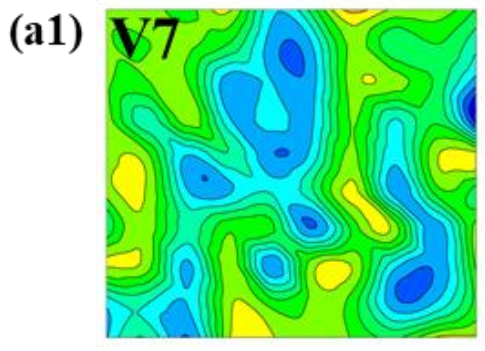

(b1)

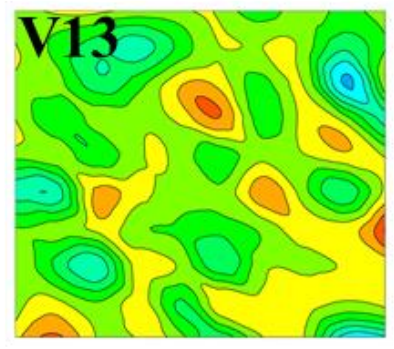

(c1)
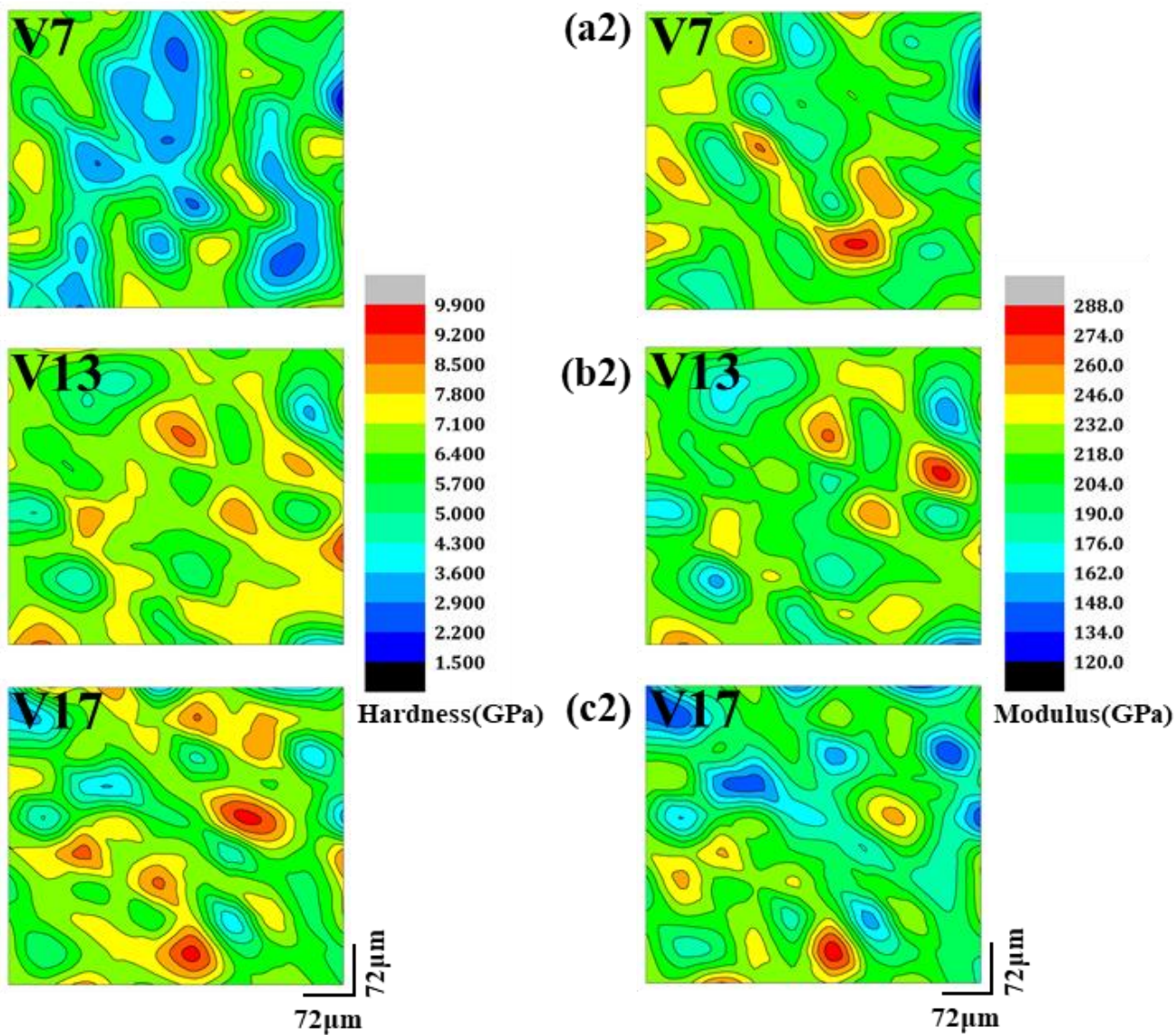

Fig. 10. Nano-hardness contour map of (a1) V7, (b1) V13 and (c1) V17; Elastic modulus contour map of (a2) V7, (b2) V13 and (c2) V17.

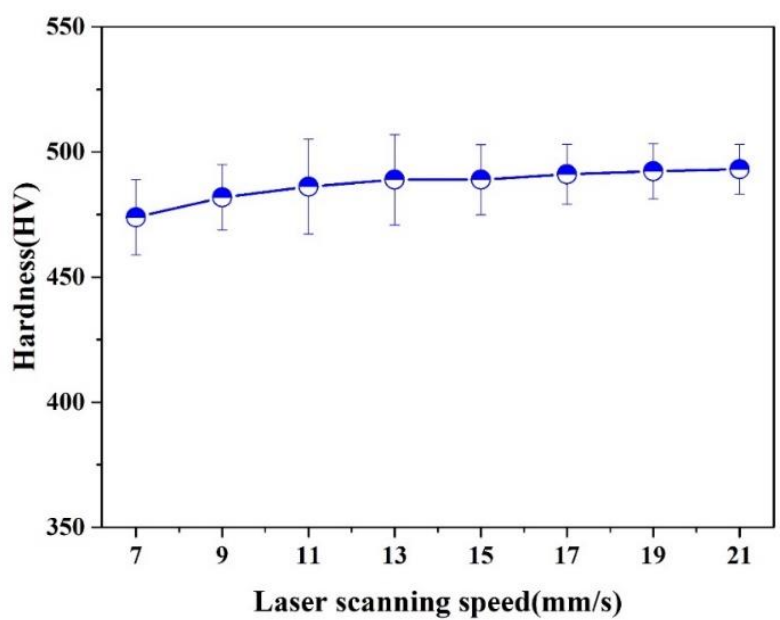

Fig. 11. Microhardness of $\mathrm{Al}_{16.80} \mathrm{Co}_{20.74} \mathrm{Cr}_{20.49} \mathrm{Fe}_{21.28} \mathrm{Ni}_{20.70} \mathrm{HEA}$ coatings. 
Table 3 Hardness and Elastic modulus of different phases in V7, V13 and V17

\begin{tabular}{|c|c|c|c|c|c|c|c|c|c|c|c|}
\hline Coatings & Area & Phases & $\begin{array}{c}\text { Displacement } \\
(\mathrm{nm})\end{array}$ & $\begin{array}{c}\text { Hardness } \\
(\mathrm{H}) \\
(\mathrm{GPa})\end{array}$ & $\begin{array}{c}\text { Elastic } \\
\text { Modulus } \\
(\mathrm{E}) \\
(\mathrm{GPa})\end{array}$ & $\begin{array}{l}\text { Number } \\
\text { of } \\
\text { Indents } \\
\text { (n) }\end{array}$ & $\begin{array}{c}\text { CV } \\
\text { Hardness } \\
(\%)\end{array}$ & $\begin{array}{c}\mathrm{CV} \\
\text { Elastic } \\
\text { Modulus } \\
(\%)\end{array}$ & $\begin{array}{c}\text { Reduced } \\
\text { Elastic } \\
\text { Modulus } \\
\left(\mathrm{E}_{\mathrm{r}}\right) \\
(\mathrm{GPa}) \\
\end{array}$ & $\mathrm{H} / \mathrm{E}_{\mathrm{r}}$ & $\mathrm{H}^{3} / \mathrm{E}_{\mathrm{r}}^{2}$ \\
\hline \multirow{3}{*}{ V7 } & $\mathrm{W}$ & FCC & $340 \pm 40$ & $3 \pm 1$ & $200 \pm 30$ & 33 & \multirow{3}{*}{40} & \multirow{3}{*}{9} & 182 & 0.015 & 0.000675 \\
\hline & NP-M & FCC-BCC & $280 \pm 10$ & $5 \pm 1$ & $225 \pm 35$ & 16 & & & 202 & 0.022 & 0.002469 \\
\hline & M & BCC & $250 \pm 10$ & $7 \pm 1$ & $240 \pm 30$ & 40 & & & 213 & 0.029 & 0.005955 \\
\hline \multirow{3}{*}{ V13 } & GB & FCC & $310 \pm 40$ & $5 \pm 1$ & $176 \pm 28$ & 21 & \multirow{3}{*}{24} & \multirow{3}{*}{15} & 163 & 0.028 & 0.004035 \\
\hline & NP-M & FCC-BCC & $262 \pm 10$ & $6 \pm 1$ & $219 \pm 21$ & 37 & & & 197 & 0.027 & 0.004504 \\
\hline & M & $\mathrm{BCC}$ & $239 \pm 15$ & $8 \pm 2$ & $242 \pm 34$ & 43 & & & 214 & 0.033 & 0.008743 \\
\hline \multirow{3}{*}{ V17 } & GB & FCC & $314 \pm 42$ & $5 \pm 1$ & $169 \pm 33$ & 26 & \multirow{3}{*}{24} & \multirow{3}{*}{16} & 158 & 0.029 & 0.004377 \\
\hline & NP-M & FCC-BCC & $262 \pm 11$ & $6 \pm 1$ & $217 \pm 31$ & 40 & & & 196 & 0.028 & 0.004587 \\
\hline & M & BCC & $238 \pm 18$ & $8 \pm 2$ & $237 \pm 44$ & 33 & & & 211 & 0.034 & 0.009115 \\
\hline
\end{tabular}


The mechanical properties of the individual phase of coatings were systematically studied. The nanoindentation responses of V7 and V13 were shown in Fig. 12 and Fig. 14, respectively. Fig. 12 showed the SEM morphology of V7 after indentation. There were three characteristic phases in V7, Widmanstätten (W), Matrix (M) and the mixed structure of Nanoprecipitates and Matrix (NP-M). The high magnification SEM images of the representative indents of W, M and NP-M were shown in Fig. 12 (b), (c) and (d), which were marked by the yellow boxes in Fig. 12(a). It was worth noting that the nanoprecipitates were observed at the indent of NP-M (see Fig. 12(c)). The load-displacement curves of them were shown in Fig. 13. Under the same load condition $(10 \mathrm{mN}), \mathrm{W}$ had the deepest indentation depth, NP-M had the middle indentation depth, and $M$ had the smallest indentation depth. 33 indents were measured in the $\mathrm{W}$ phase, 16, 40 indents were also measured in the other two phases M, NP-M, and similar indentation depth results were obtained (Table 3). Thus, W was identified as softer than M and NP-M; while M was the hardest phase and had better resistance to deformation. In summary, the hardness of different phases was very different. It may be attributed to the different crystal structures of the three phases. From the above chapter, W, M and NP-M phases were FCC structure, BCC structure and FCC-BCC structure respectively. BCC structure generally has a larger hardness value and superior strength than the FCC phase [36,37]. Interestingly, the difference in nano-hardness of the three phases can be reflected by the indentation size effect (ISE), which reveals that the reduction in the size of the indentation leads to an increase in nano-hardness and a decrease in plasticity [38]. As shown in Fig. 12 (a), the indentation area of $\mathrm{W}$ phase was larger than that of M phase and NP-M phase. Table 3 showed the exact value of elastic modulus, E (GPa) and hardness, H (GPa) for W, M and NP-M. The values of elastic modulus and nano-hardness were calculated by the Oliver-Pharr method [39]. The difference in elastic modulus of each phases was not as obvious as that in hardness value, easy to identify from the coefficient of variation $(\mathrm{CV})$ of hardness and elastic modulus listed in Table 3. 

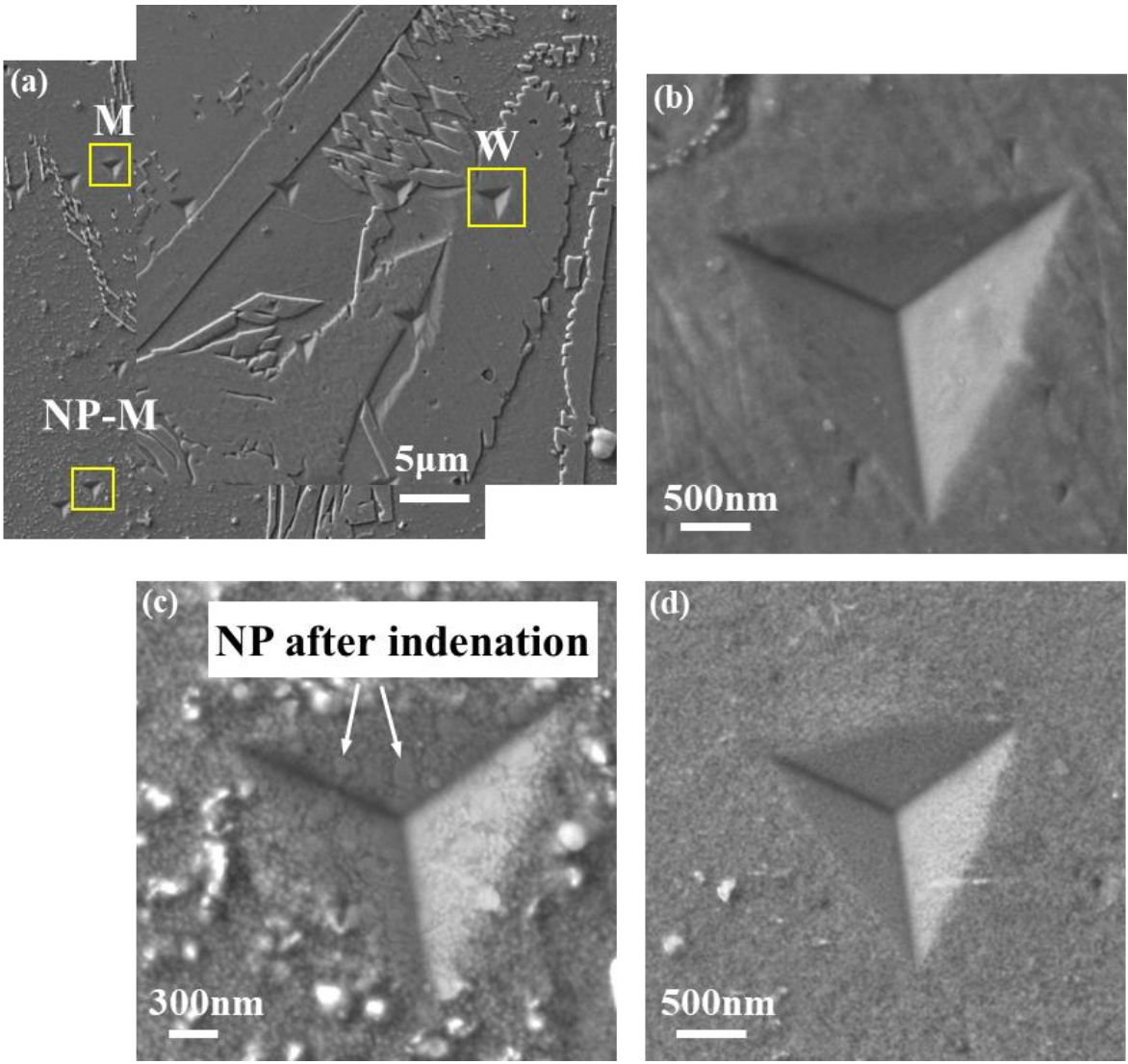

Fig. 12. (a) SEM morphology of V7 after indentation, and the high magnification

SEM images of the representative indents of (b) Widmanstätten (W), (c)

Nanoprecipitates and Matrix mixed structure (NP-M) and (d) Matrix (M) (marked by boxes in Fig. 12(a)).

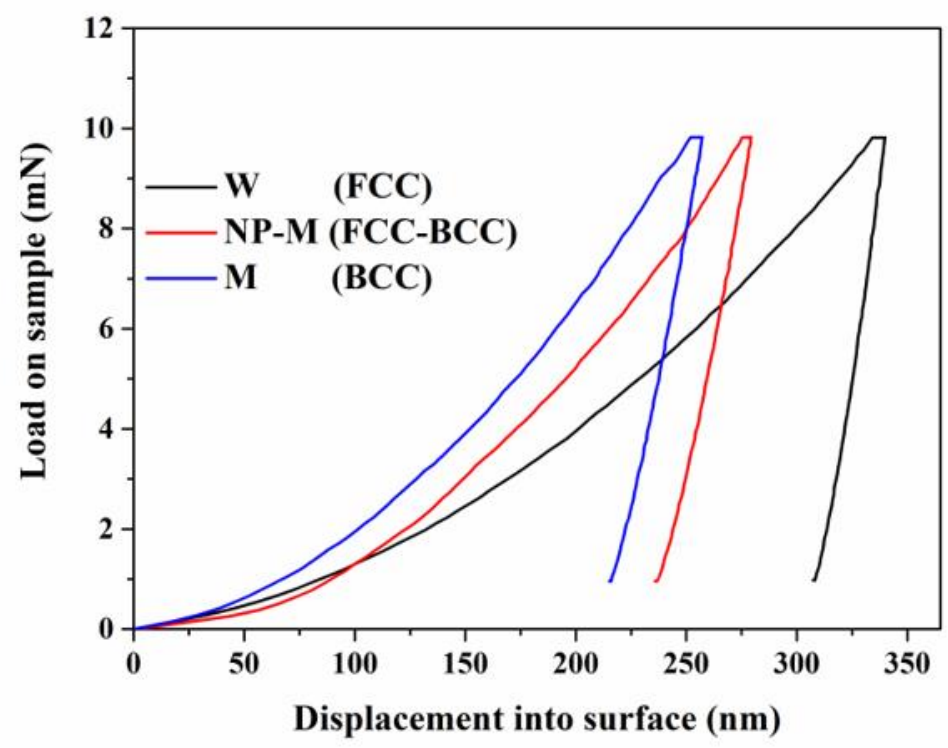


Fig. 13. Load-displacement curves of the representative indents of Widmanstätten (W), Matrix (M) and Nanoprecipitates and matrix mixed structure (NP-M) in V7

The SEM morphologies of V13 after indentation were shown in Fig .14. The three characteristic phases, Grain Boundary (GB), Matrix (M) and Nanoprecipitates and Matrix mixed structure (NP-M) were FCC, BCC and FCC-BCC structure respectively. Grain boundaries and nanoprecipitates after indentation can be clearly observed in Fig. 14 (b) and (c). The load-displacement curves were shown in Fig. 15. GB displayed the largest displacement, followed by M and NP-M. This is consistent with the research results of V7 that the FCC structure has a larger indentation depth than the BCC structure. But it was noticed that the indentation depth of GB was less than W (see Fig. 13).

The exact values of the elastic modulus and nano-hardness of each phase in V17 were listed in Table 3. The characteristic phases of it were the same as those of V13, so detailed introduction will not be given here. Multiple indentations were performed on these three characteristic phases of V13 and V17, respectively, the CV of hardness and elastic modulus were listed in Table 3. 

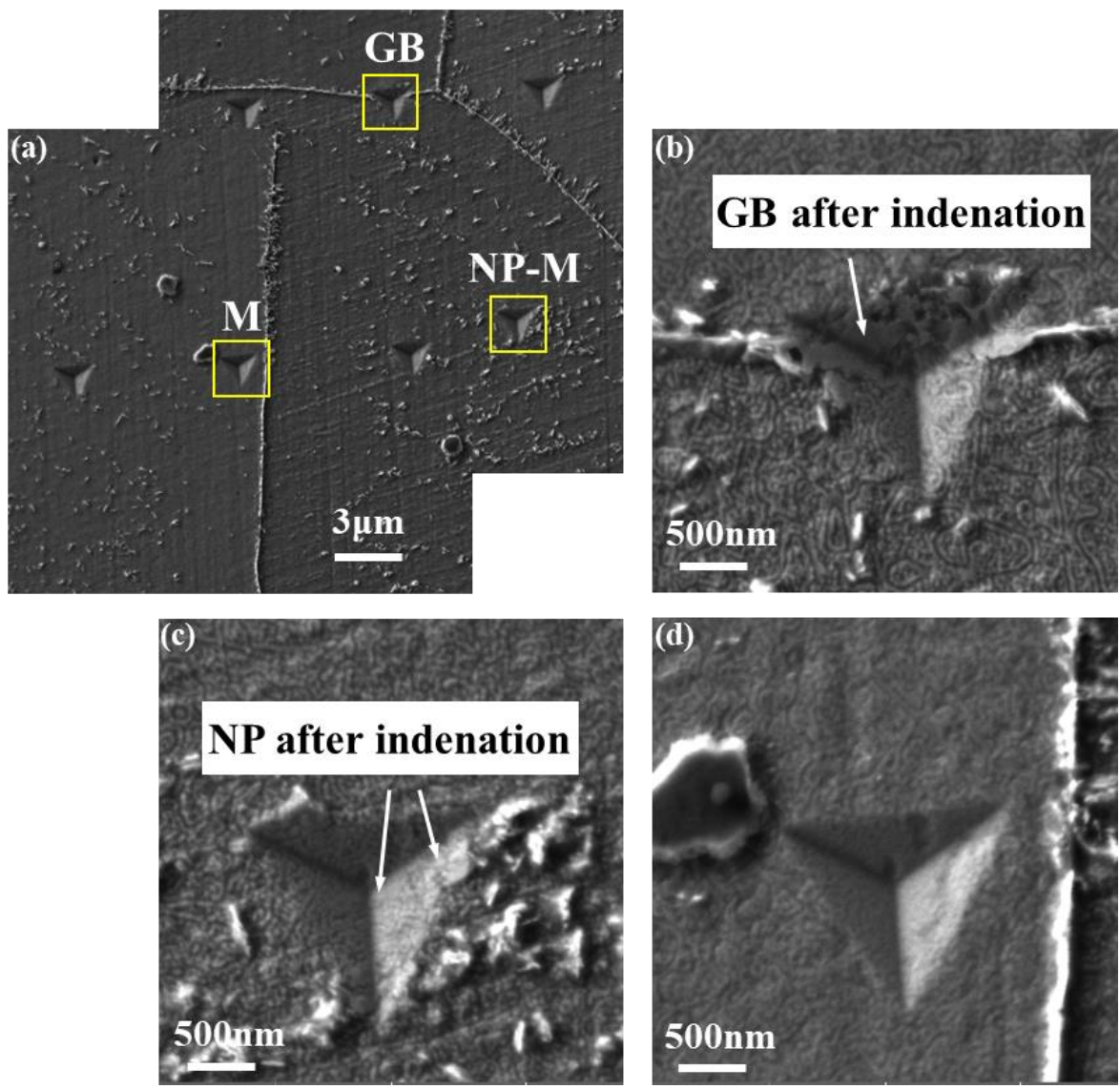

Fig. 14. (a) SEM morphology of V13 after indentation, and the high magnification SEM images of the representative indents of (b) Grain Boundary (GB), (c) Nanoprecipitates and Matrix mixed structure (NP-M) and (d) Matrix (M) (marked by boxes in Fig. 14(a)).

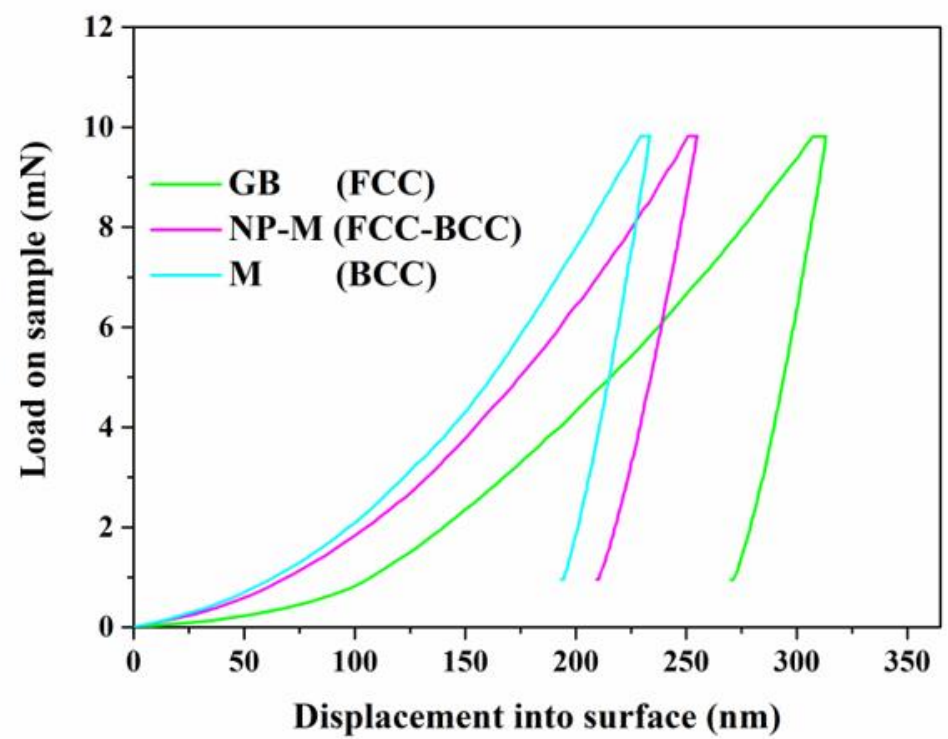

Fig. 15. Load-displacement curves of the representative indents of Grain Boundary 
(GB), matrix (M) and Nanoprecipitates and Matrix mixed structure (NP-M) in V13.

Moreover, the load-displacement curves corresponding to V7 and V13 were not smooth especially in M phases and NP-M phases (see Fig.13 and Fig.15), which is a phenomenon of the serrations [40]. It indicates that a deformation mechanism that hinders the movement of dislocations may be formed in the coatings. The possible strengthening mechanisms are dispersion strengthening in the mixed structure of nanoprecipitates phases and matrix phases, and solid solution strengthening in the matrix phases.

The nanoindentation results in the literature were depicted in Fig. 16 [16,41-43]. It should be noted, here, we only focus on nano-hardness and elastic modulus of Al-Co-Cr-Fe-Ni HEAs. The comparison results obviously revealed that $\mathrm{Al}_{16.80} \mathrm{Co}_{20.74} \mathrm{Cr}_{20.49} \mathrm{Fe}_{21.28} \mathrm{Ni}_{20.70}$ HEA coatings have the best combination of namo-hardness and elastic modulus combination of the nano-hardness and elastic modulus superior to that of other Al-Co-Cr-Fe-Ni HEAs. This may be due to the special microstructure of the coating in this experiment. in which the nanoprecipitates are distributed in the equiaxed matrix grains with $\mathrm{A} 2$ and $\mathrm{B} 2$ structures.

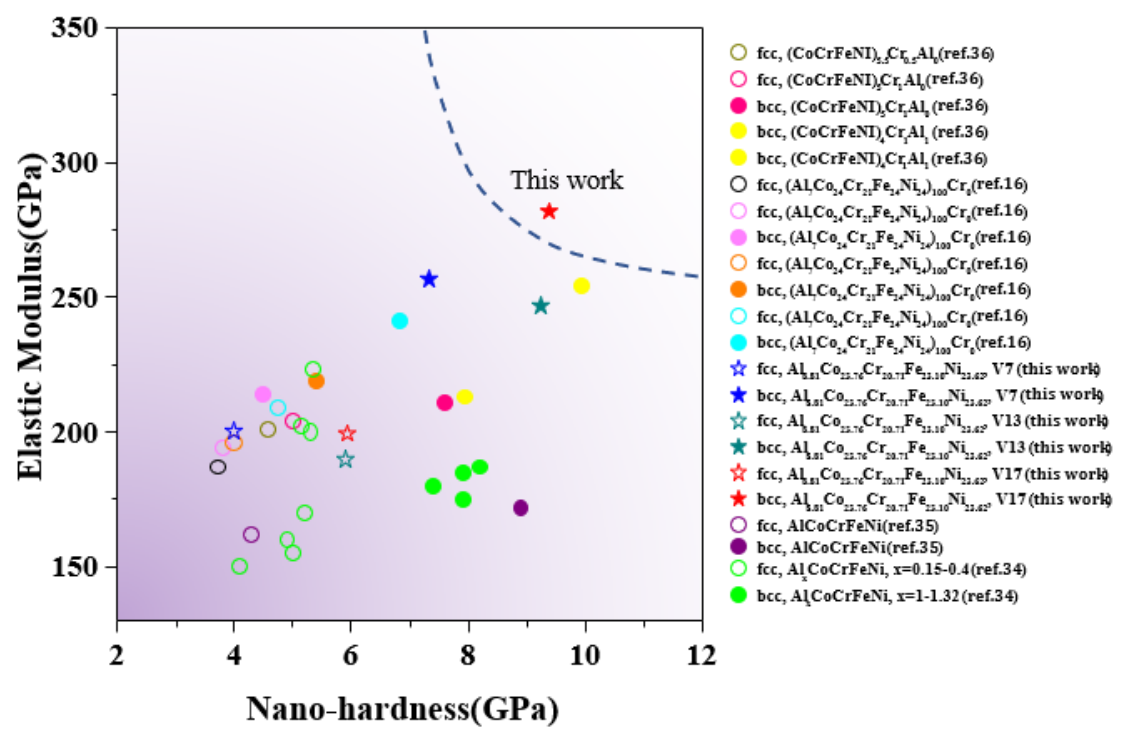

Fig. 16 Nano-hardness and elastic modulus of FCC and BCC phases compared with those of other Al-Co-Cr-Fe-Ni HEA alloys [16,41-43]. Open and solid symbols represent the value of FCC and BCC, respectively. The open and closed symbols of the same color were from the same material. 


\subsection{Wear test}

$\mathrm{H} / \mathrm{E}_{\mathrm{r}}$ and $\mathrm{H}^{3} / \mathrm{E}_{\mathrm{r}}{ }^{2}$ are the suitable parameters for evaluating wear resistance, and $\mathrm{H}^{3} / \mathrm{E}_{\mathrm{r}}^{2}$ can reflect the ability to resist plastic deformation [44]. Here, $\mathrm{E}_{\mathrm{r}}$ refers to reduced elastic modulus, which is calculated by the following formula: $\left(E_{r}\right)^{-1}=\left(E_{s}\right)^{-1}\left(1-v_{s}^{2}\right)+\left(E_{i}\right)^{-1}\left(1-v_{i}^{2}\right)$, where $E_{s}$ and $E_{i}$ are the elastic modulus of the specimen and indenter, respectively; $v_{s}$ and $v_{i}$ were the Poisson's ratio of the specimen and indenter, respectively; The $E_{i}$ and $v_{i}$ were $1147 \mathrm{GPa}$ and 0.3 in turn. The calculated values of $\mathrm{E}_{\mathrm{r}}, \mathrm{H} / \mathrm{E}_{\mathrm{r}}$ and $\mathrm{H}^{3} / \mathrm{E}_{\mathrm{r}}{ }^{2}$ were exhibited in Table 3. The $\mathrm{H} / \mathrm{E}_{\mathrm{r}}$ and $\mathrm{H}^{3} / \mathrm{E}_{\mathrm{r}}^{2}$ value of each phase of $\mathrm{V} 17$ was the highest among the three coatings. According to the mixing principle, V17 should have the best wear resistance.

The wear performance of the coatings was evaluated by the dry sliding friction test. The V7, V13, and V17 were subjected to dry sliding friction tests both at room temperature and $800^{\circ}$. The friction coefficient curves were shown in Fig. 17 (a) and (b), respectively. The room temperature friction coefficients calculated statistically of V7, V13, and V17 were $0.73,0.49$ and 0.51 , respectively. The friction coefficients at $800^{\circ} \mathrm{C}$ were $0.18,0.12$ and 0.10 , respectively. The friction coefficient at room temperature is $4.06,4.08$, and 5.10 times of the friction coefficient at high temperature in turn. The high-entropy alloy coating has a smaller coefficient of friction at high temperatures. Moreover, regardless of whether it is at room temperature or $800^{\circ} \mathrm{C}$, the friction coefficient of the coating gradually decreases with the increase of the laser scanning speed, and the friction coefficient of V13 was much smaller than V7.

In order to measure wear resistance more accurately, the wear profile of the coating was measured [45]. 30 wear profiles were measured for each wear sample to ensure the authenticity of the data, and then the Origin software was used to average multiple curves to get the ultimate wear profile curve, as shown in Fig. 17(c). It can be seen from the wear profile that, from V7 to V17, the width and depth of the wear track of the coatings gradually decrease, indicating that the amount of wear volume 


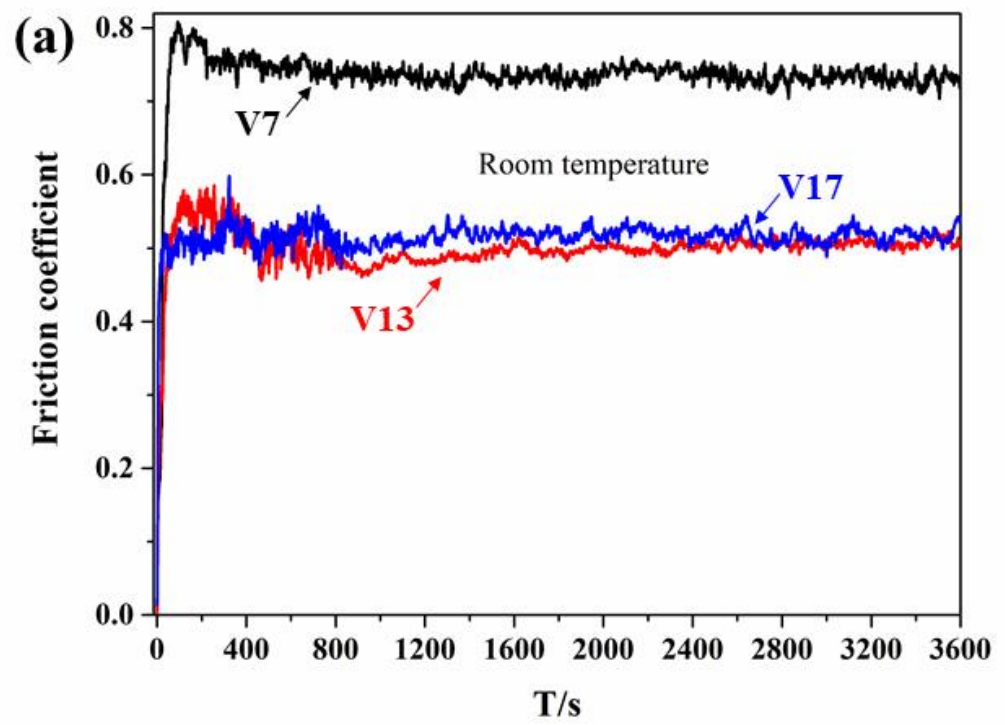



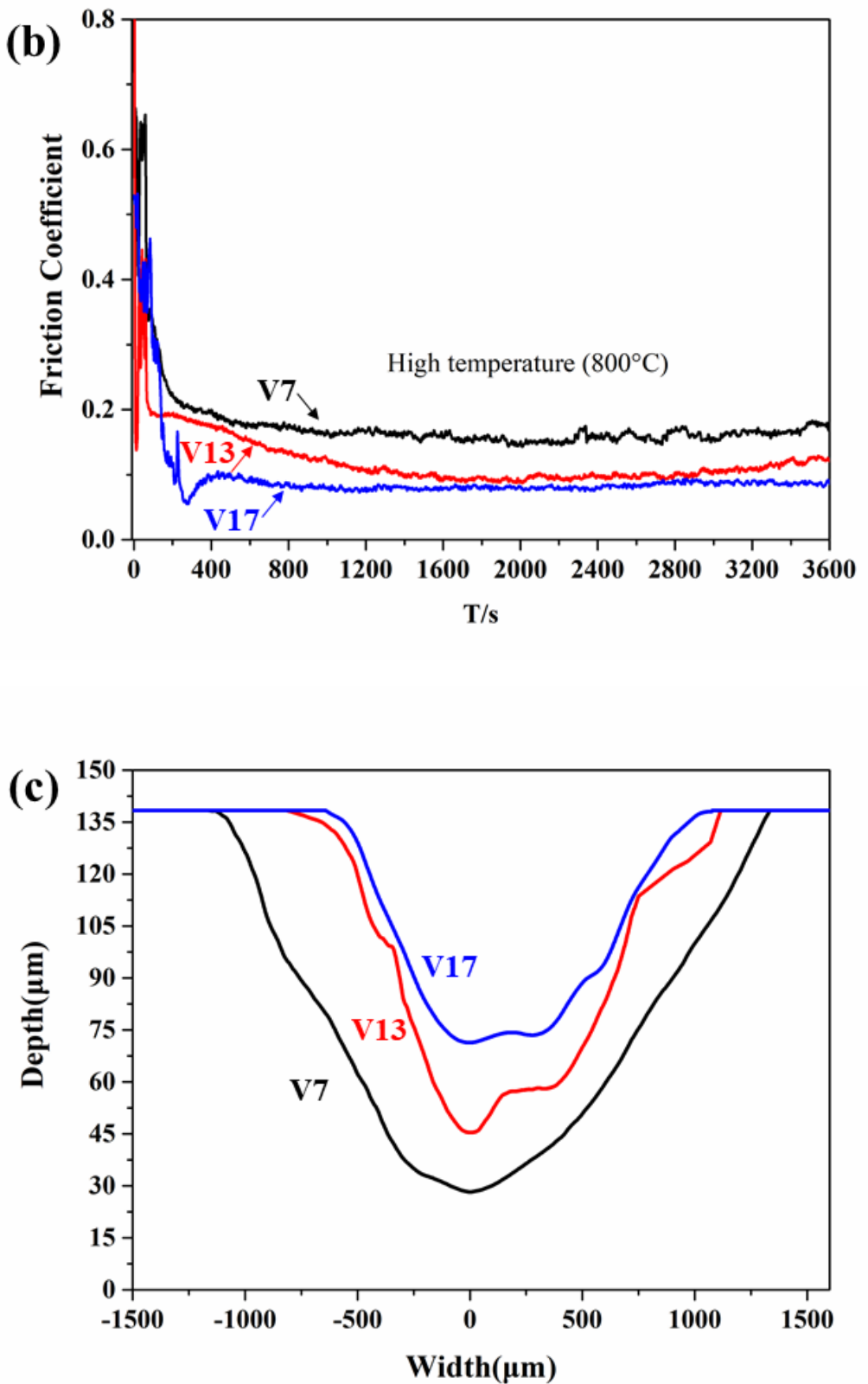


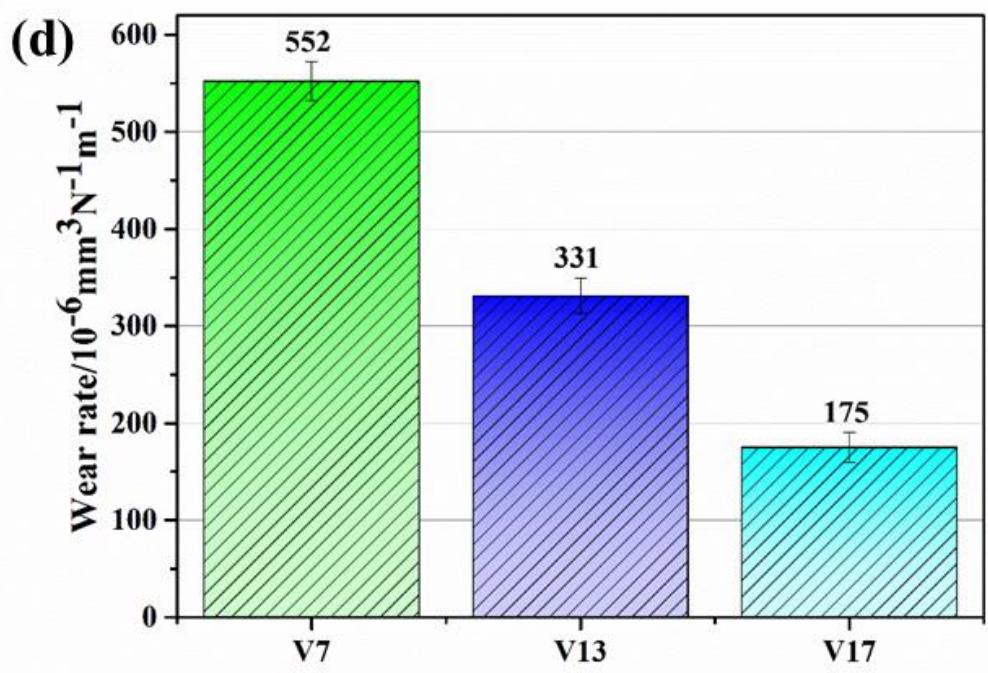

Fig. 17. (a) Room temperature friction and wear curve; (b) High temperature $\left(800^{\circ} \mathrm{C}\right)$ friction and wear curve; (c) Wear scar profile curve of V7, V13 and V17 at $800^{\circ} \mathrm{C}$ and (d) The wear rate of $\mathrm{V} 7, \mathrm{~V} 13$ and $\mathrm{V} 17$ at $800^{\circ} \mathrm{C}$.
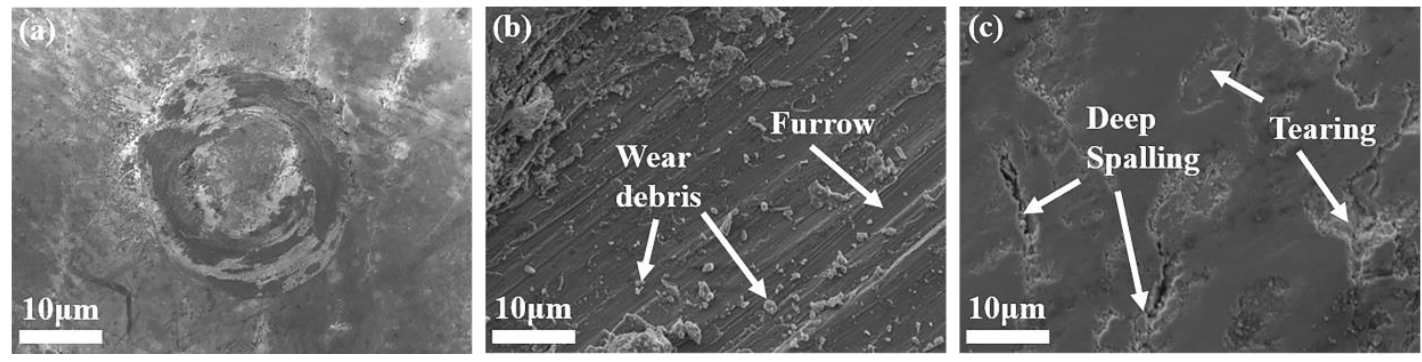

Fig. 18. The wear morphology of V17.

\section{Discussion}

\subsection{Phase transformation}

In order to predict phase formation in multi-component HEAs, some parameters had been published. From the perspective of thermodynamics, Zhang et al. [4] proposed two parameters $\Delta H_{\text {mix }}$ (enthalpy of mixing) and $\delta$ (atomic radius difference) to evaluate the solid solution forming ability, $\Delta H_{\operatorname{mix}}$ and $\delta$ are expressed as Equation (1) and (2):

$$
\Delta H_{\operatorname{mix}}=\sum_{\mathrm{i}=1, \mathrm{i} \neq \mathrm{j}}^{\mathrm{n}} 4 c_{i} c_{j} \Delta H_{i j}^{\operatorname{mix}}
$$




$$
\bar{r}=\sum_{i=1}^{n} c_{i} r_{i}
$$

where $c_{i}$ and $c_{i}$ are the atomic percentage and $\Delta H_{i j}^{m i x}$ is the enthalpy of mixing between the ith and $j$ th elements, and $r_{i}$ is the Goldschmidt atomic radius of the ith element. The parameter $\delta$ characterizes the atomic size mismatch, which produces the local elastic strain and determines the system topological instability. And the parameter $\Delta H_{\text {mix }}$ reflects the tendency of forming stable intermetallic compounds [27]. The standard for forming a mixture of ordered and disordered solid solutions are $-20<\Delta H_{m i x}<0 \mathrm{KJ} \mathrm{mol}^{-1}, 5 \%<\delta<6.6 \%$ [4]. r and $\Delta H_{i j}^{m i x}$ listed in Table 4 and Table 5 were substituted into the above formulas. And then the $\Delta H_{\text {mix }}$ and $\delta$ of $\mathrm{Al}_{16.80} \mathrm{Co}_{20.74} \mathrm{Cr}_{20.49} \mathrm{Fe}_{21.28} \mathrm{Ni}_{20.70}$ HEA coatings were calculated as $-11.23 \mathrm{KJ} \mathrm{mol}^{-1}$ and $5.43 \%$ respectively, which may fall into the ordered and disordered solid solutions mixed region. In fact, the coatings consist disordered solid solution FCC phase, solid solution BCC phase. It shows that this standard can accurately predict the phase formation of this alloy system.

Table 4 The values of mixing enthalpy of element pairs

\begin{tabular}{|c|c|c|c|c|c|}
\hline \multirow[t]{2}{*}{ Element } & \multicolumn{5}{|c|}{$\Delta \mathrm{H}_{\operatorname{mix}}(\mathrm{kJ} / \mathrm{mol})$} \\
\hline & $\mathrm{Fe}$ & $\mathrm{Co}$ & $\mathrm{Cr}$ & $\mathrm{Ni}$ & $\mathrm{Al}$ \\
\hline \multicolumn{6}{|l|}{$\mathrm{Fe}$} \\
\hline Co & -1 & & & & \\
\hline $\mathrm{Cr}$ & -1 & -4 & & & \\
\hline $\mathrm{Ni}$ & -2 & 0 & -7 & & \\
\hline $\mathrm{Al}$ & -11 & -19 & -10 & -22 & \\
\hline
\end{tabular}

Table 5 Characteristics of each element used in this paper

Element Atomic Radius $(\AA) \quad$ Crystal $\quad$ VEC Melting point $\left({ }^{\circ} \mathrm{C}\right)$




\begin{tabular}{ccccc}
\hline $\mathrm{Fe}$ & 1.241 & BCC/FCC & 8 & 1538 \\
$\mathrm{Co}$ & 1.251 & $\mathrm{HCP}$ & 9 & 1492 \\
$\mathrm{Cr}$ & 1.249 & $\mathrm{BCC}$ & 6 & 1890 \\
$\mathrm{Ni}$ & 1.246 & $\mathrm{FCC}$ & 10 & 1453 \\
$\mathrm{Al}$ & 1.432 & $\mathrm{BCC}$ & 3 & 660 \\
\hline
\end{tabular}

Furthermore, a new parameter, $\Omega$, expressing the competition between entropy and enthalpy, had been proposed by Yang et al [48]. And the author gives the criteria for forming the single stabilized solid solution, $\Omega \geq 1, \delta \leq 6.6 \%$. $\Omega$ were defined as:

$$
\begin{gathered}
\Omega=\frac{T_{m} \Delta S_{\text {mix }}}{\| \Delta H_{\operatorname{mix}} \mid} \\
T_{m}=\sum_{i=1}^{n} c_{i}\left(T_{m}\right)_{i} \\
\Delta S_{\text {mix }}=-R \sum_{i=1}^{n} c_{i} L n c_{i}
\end{gathered}
$$

where $T_{m}$ is the average melting temperature, $\left(T_{m}\right)_{i}$ is the melting point of the ith element, $\Delta S_{\text {mix }}$ is the mixing entropy and $\mathrm{R}\left(8.314 \mathrm{KJ} \mathrm{mol}^{-1}\right)$ is the gas constant. The $\Omega$ of $\mathrm{Al}_{16.80} \mathrm{Co}_{20.74} \mathrm{Cr}_{20.49} \mathrm{Fe}_{21.28} \mathrm{Ni}_{20.70}$ was calculated as 1.71 listed in Table 6 . In short, the $\delta$ and $\Omega$ values of $\mathrm{Al}_{16.80} \mathrm{Co}_{20.74} \mathrm{Cr}_{20.49} \mathrm{Fe}_{21.28} \mathrm{Ni}_{20.70}$ coatings are $5.43 \%$ and 1.71. According to $\Omega$ and $\delta$ criteria, the single-phase solid solution will be generated. However, the coatings consist of disordered solid solution FCC phase, solid solution BCC phase with ordered B2 structure. Therefore, the $\Omega$ and $\delta$ criteria is not appropriate to predict the phase formation in this HEA system.

It should be noted that for laser cladding, due to the dilution from the substrate, using the present criterions suitable to the alloys processed by the traditional casting and smelting method will cause the phase prediction results to be inaccurate. Juan et al. [49] proposed the modified criterions of the solid-solution formation ability in the multi-component laser-clad coatings : $10.8 \leq \triangle \mathrm{Smix} \leq 16.2 \mathrm{~J} \cdot \mathrm{K}^{-1} \cdot \mathrm{mol}^{-1},-17 \leq \triangle$ Hmix $\leq 7 \mathrm{~kJ} \cdot \mathrm{mol}^{-1}, 0 \leq \delta \leq 14$. According to this standard, combined with Table 6 , the coating can form a solid solution, which is consistent with the phase structure of the 
coatings.

In addition, Guo et al. [50] proposed a physical parameter, valence electron concentration (VEC), to predict the phase stability for FCC and $\mathrm{BCC}$ phases in HEAs. When $V E C \geq 8.0$, only FCC phase exists; when $6.87 \leq V E C<8.0$, mixed FCC and BCC phases will co-exist; only BCC phase exists when $V E C<6.87$. The $V E C$ of the system is calculated by the following equation:

$$
V E C=\sum_{i=1}^{n} c_{i}(V E C)_{i}
$$

where $c_{i}$ is the atomic percentage and $(V E C)_{i}$ is the VEC of the $i$ th element. The calculated VEC value of $\mathrm{Al}_{16.80} \mathrm{Co}_{20.74} \mathrm{Cr}_{20.49} \mathrm{Fe}_{21.28} \mathrm{Ni}_{20.70} \mathrm{HEA}$ coatings is 7.37, falling into the region of mixed FCC and BCC phases. And the coating is a mixture of FCC and $\mathrm{BCC}$ phases, implying that the phase stability for $\mathrm{Al}_{16.80} \mathrm{Co}_{20.74} \mathrm{Cr}_{20.49} \mathrm{Fe}_{21.28} \mathrm{Ni}_{20.70}$ HEAs can be predicted by VEC.

The above parameters can predict whether to generate solid solutions or ordered solid solutions for $\mathrm{Al}_{16.80} \mathrm{Co}_{20.74} \mathrm{Cr}_{20.49} \mathrm{Fe}_{21.28} \mathrm{Ni}_{20.70}$ HEA coatings, as well as the structure of solid solutions, such as FCC and BCC. But the volume fraction of each phase cannot be predicted. According to the results obtained by the above chapters, we found that the increase in laser scanning speed promotes the formation of the BCC phase, as shown in Fig. 2(a) and Fig. 4, which is consistent with the results reported by M.D. et al. [51]. Wang et al. [52]and Cui et al. [28] also have a similar research report. They proposed that high volume fraction of the BCC phase can be attributed to the higher scanning speeds and high cooling rates caused by the former. The volume fraction of the BCC phase calculated by Image J software was exhibited in Fig. 19 [43], which increases with the increase of the laser scanning speed. And the coatings can be divided into three types according to the volume fraction of BCC: (1) <80\%; (2) $80 \%-90 \%$; (3) $>90 \%$. The corresponding morphologies of the three coatings were also shown in the insets in Fig. 19, in which the white sphere represents the nanoprecipitates phase, and the white needle-shaped represents the Widmanstätten side plates. When the volume fraction of $\mathrm{BCC}$ is $<80 \%$, the coatings include 


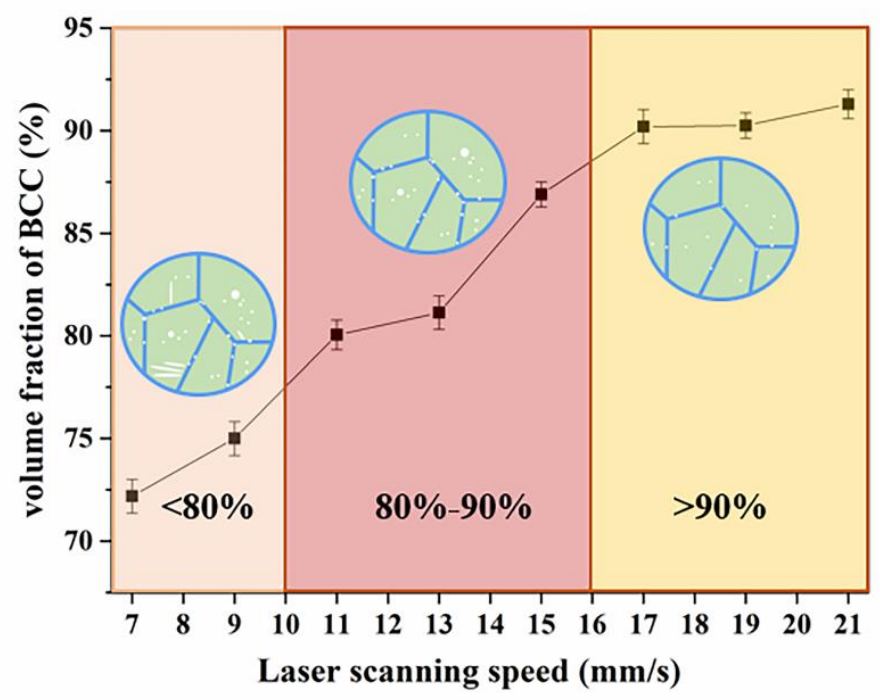

Fig. 19. The volume fraction of BCC as a function of laser scanning speed.

4.2 Relationship between the phase transformation and mechanical properties The laser scanning speed significantly improves the strength of the HEA coatings. 
With the increase of laser scanning speed, the nano-hardness exhibited a significant increase trend overall, from $5.4 \mathrm{GPa}$ to $6.6 \mathrm{GPa}$ and then to $6.4 \mathrm{GPa}$. It may be the phase transformations that cause the increase of average nano-hardness from $\mathrm{V} 7$ to V17. Fig. 19 showed that the increase of volume fraction of the BCC phase from V7 to V17. Since the nano-hardness values of the BCC phase ( $7 \pm 1 \mathrm{GPa}$ in $\mathrm{V} 7,8 \pm 2 \mathrm{GPa}$ in V13, and $8 \pm 2 \mathrm{GPa}$ in V17) are much greater than those of the FCC phase $(3 \pm$ $1 \mathrm{GPa}$ in $\mathrm{V} 7,5 \pm 1 \mathrm{GPa}$ in $\mathrm{V} 13$, and $5 \pm 1 \mathrm{GPa}$ in $\mathrm{V} 17$ ), the increased number of BCC phase will lead to an increase in the nano-hardness of the whole coating. Consistent with nano-hardness, wear resistance was also significantly improved (see Fig. 17). The increase in wear resistance and strength can be attributed to many strengthening mechanisms, such as grain boundary hardening, solid solution strengthening and second phase strengthening.

Grain boundary hardening exists in this HEA and it is related to the undercooling. The total undercooling is defined as a sum of four different contributions [53].

$$
\Delta T=\Delta T_{t}+\Delta T_{c}+\Delta T_{r}+\Delta T_{k}
$$

where $\Delta T_{t}$ represents the thermal undercooling, $\Delta T_{\sigma}$ the constitutional undercooling, $\Delta T_{r}$ the curvature undercooling, and $\Delta T_{k}$ the kinetic undercooling. In the laser cladding process, kinetic undercooling is related to laser scanning speed which can be determined by the following methods $[54,55]$ :

$$
\begin{aligned}
& \Delta T_{k}=\frac{v_{s}}{\lambda} \\
& v_{s}=a v \\
& \lambda=\frac{\Delta H_{f} v_{0}}{k_{B} T_{L}^{2}} \\
& \sigma_{y}=\sigma_{0}+k D^{-1 / 2}
\end{aligned}
$$


where $v$ is laser scanning speed, $v_{s}$ is the growth velocity of solidification front, a is a constant defined by us $(>1), \lambda$ is the interfacial kinetic coefficient, $v_{0}$ is the speed of sound $(\mathrm{m} / \mathrm{s}), k_{B}$ is the Boltzmann constant, $\Delta H_{f}$ is the standard molar enthalpy of formation, and $\Delta H_{f}$ is the liquidus temperature (K). From equation (9) and (10), increased laser scanning speed will greatly increase the kinetic undercooling in the melt pool. According to the solidification theory [56], a large kinetic undercooling will lead to a significant increase in the nucleation rate. A large amount of nucleation in a limited time leads to insufficient time for grain growth, thus, refining the grains of HEA coatings [57]. As mentioned above (see Fig. 5), the grain size keeps decreasing with increasing laser scanning speed. Therefore, grain boundary strengthening occurs in the coating, having a great contribution to the excellent performance of coatings. At the same time, grain boundary strengthening can be calculated quantitatively with the Hall-Patch formula (Eq. 12) [58]. The specific inquiry is expected in the following research.

\section{Conclusions}

Low-cost $\mathrm{Al}_{16.80} \mathrm{Co}_{20.74} \mathrm{Cr}_{20.49} \mathrm{Fe}_{21.28} \mathrm{Ni}_{20.70}$ HEA coatings were processed by laser cladding. The phase formation, microstructure evolution, and mechanical behaviors of these HEA coatings were investigated. The following conclusions were drawn as follows:

(1) All alloys were typical polycrystalline structures composed of equiaxed matrix grains with BCC structure. White nanoprecipitates are distributed in the grain boundary and inside the grain as a precipitated phase. And the nanoprecipitates were $\mathrm{Cr}$-rich FCC precipitate phases. The BCC structures in V17 were composed of 55\% B2 structure and 45\% A2 structure.

(2) The evolution of the phase and microstructure of coatings has been discovered. As the laser scanning speed increases, the volume fraction of 
the BCC structure gradually increases. The coatings can be divided into three types according to the volume fraction of BCC: (1) V7-V9 (<80\%): Widmanstätten side plate (FCC), nanoprecipitates phase (FCC) and matrix phase (BCC); (2) V11-V15 (80\%-90\%): nanoprecipitates phase (FCC) and matrix phase (BCC); (3) V17-V21(>90\%): less and finer nanoprecipitates phase (FCC) and matrix phase (BCC). The grain size of equiaxed grains reduced from $276 \mu \mathrm{m}$ to $42 \mu \mathrm{m}$ with increased laser scanning speed.

(3) Nanoindentation measurements were performed on V7, V13 and V17, respectively. The nano-hardness values of the $\mathrm{BCC}$ phase $(7 \pm 1 \mathrm{GPa}$ in $\mathrm{V} 7,8 \pm 2 \mathrm{GPa}$ in $\mathrm{V} 13$, and $8 \pm 2 \mathrm{GPa}$ in $\mathrm{V} 17$ ) were much greater than those of the FCC phase $(3 \pm 1 \mathrm{GPa}$ in $\mathrm{V} 7,5 \pm 1 \mathrm{GPa}$ in $\mathrm{V} 13$, and $5 \pm 1 \mathrm{GPa}$ in V17).

(4) The coating has better wear resistance at high temperatures, and the wear resistance of V17 is the best among the three coatings, consistent with the predicted results by $\mathrm{H} / \mathrm{E}_{\mathrm{r}}$ and $\mathrm{H}^{3} / \mathrm{E}_{\mathrm{r}}{ }^{2}$.

(5) The excellent mechanical properties for V17 lie in grain boundary strengthening, increased laser scanning speed will greatly increase the kinetic undercooling in the melt pool, which increases the nucleation rate and refine the grain.

\section{Acknowledgments}

This research was supported by Foundation of Natural Science Foundation of China (52075317, 51905333, 51805316), the Royal Society through International Exchanges 2018 Cost Share (China) scheme (IECINSFCl181278), Shanghai Sailing Program (19YF1418100), Shanghai Science and Technology Committee Innovation Grant (17JC1400600，17JC1400601, 19511106400, 19511106402), Karamay Science and Technology Major Project (2018ZD002B), Aid for Xinjiang Science and Technology Project (2019E0235), Shanghai local colleges and universities capacity building special plan project (19030501300). 


\section{References}

[1] J.W. Yeh, S.K. Chen, S.J. Lin, J.Y. Gan, T.S. Chin, T.T. Shun, C.H. Tsau, S.Y. Chang, Nanostructured high-entropy alloys with multiple principal elements: Novel alloy design concepts and outcomes, Adv. Eng. Mater. 6 (2004) 299-303. https://doi.org/10.1002/adem.200300567.

[2] K. Xiang, L.Y. Chen, L. Chai, N. Guo, H. Wang, Microstructural characteristics and properties of CoCrFeNiNbx high-entropy alloy coatings on pure titanium substrate by pulsed laser cladding, Appl. Surf. Sci. 517 (2020) 146214. https://doi.org/10.1016/j.apsusc.2020.146214.

[3] T.M. Yue, H. Xie, X. Lin, H.O. Yang, G.H. Meng, Solidification behaviour in laser cladding of $\mathrm{AlCoCrCuFeNi} \mathrm{high-entropy} \mathrm{alloy} \mathrm{on} \mathrm{magnesium} \mathrm{substrates,}$ J. Alloys Compd. 587 (2014) 588-593. https://doi.org/10.1016/j.jallcom.2013.10.254.

[4] Y. Zhang, Y.J. Zhou, J.P. Lin, G.L. Chen, P.K. Liaw, Solid-solution phase formation rules for multi-component alloys, Adv. Eng. Mater. 10 (2008) 534-538. https://doi.org/10.1002/adem.200700240.

[5] J. Cheng, B. Sun, Y. Ge, X. Hu, L. Zhang, X. Liang, X. Zhang, Nb doping in laser-cladded $\mathrm{Fe} 25 \mathrm{Co} 25 \mathrm{Ni} 25(\mathrm{~B} 0.7 \mathrm{Si} 0.3) 25$ high entropy alloy coatings: Microstructure evolution and wear behavior, Surf. Coatings Technol. 402 (2020) 126321. https://doi.org/10.1016/j.surfcoat.2020.126321.

[6] J. Wang, B. Zhang, Y. Yu, Z. Zhang, S. Zhu, X. Lou, Z. Wang, Study of high temperature friction and wear performance of (CoCrFeMnNi)85Ti15 high-entropy alloy coating prepared by plasma cladding, Surf. Coatings Technol. 384 (2020) 125337. https://doi.org/10.1016/j.surfcoat.2020.125337.

[7] H. Yao, Z. Tan, D. He, Z. Zhou, Z. Zhou, Y. Xue, L. Cui, L. Chen, G. Wang, Y. Yang, High strength and ductility AlCrFeNiV high entropy alloy with hierarchically heterogeneous microstructure prepared by selective laser melting, J. Alloys Compd. 813 (2020) 152196. https://doi.org/10.1016/j.jallcom.2019.152196. 
[8] Y.Q. Jiang, J. Li, Y.F. Juan, Z.J. Lu, W.L. Jia, Evolution in microstructure and corrosion behavior of AlCoCrxFeNi high-entropy alloy coatings fabricated by laser cladding, J. Alloys Compd. 775 (2019) 1-14. https://doi.org/10.1016/j.jallcom.2018.10.091.

[9] S. Xie, R. Li, T. Yuan, L. Zhou, M. Zhang, M. Wang, P. Niu, P. Cao, C. Chen, Effect of heating rate on microstructure and mechanical properties of AlCoCrFeNi high entropy alloy produced by spark plasma sintering, Mater. Charact. 154 (2019) 169-180. https://doi.org/10.1016/j.matchar.2019.05.022.

[10] Q. Chao, T. Guo, T. Jarvis, X. Wu, P. Hodgson, D. Fabijanic, Direct laser deposition cladding of AlxCoCrFeNi high entropy alloys on a high-temperature stainless steel, Surf. Coatings Technol. 332 (2017) 440-451. https://doi.org/10.1016/j.surfcoat.2017.09.072.

[11] X. Li, Y. Feng, B. Liu, D. Yi, X. Yang, W. Zhang, G. Chen, Y. Liu, P. Bai, Influence of $\mathrm{NbC}$ particles on microstructure and mechanical properties of AlCoCrFeNi high-entropy alloy coatings prepared by laser cladding, J. Alloys Compd. 788 (2019) 485-494. https://doi.org/10.1016/j.jallcom.2019.02.223.

[12] W.R. Wang, W.L. Wang, J.W. Yeh, Phases, microstructure and mechanical properties of AlxCoCrFeNi high-entropy alloys at elevated temperatures, $\mathrm{J}$. Alloys Compd. 589 (2014) 143-152. https://doi.org/10.1016/j.jallcom.2013.11.084.

[13] J. Joseph, N. Stanford, P. Hodgson, D.M. Fabijanic, Understanding the mechanical behaviour and the large strength/ductility differences between FCC and BCC AlxCoCrFeNi high entropy alloys, J. Alloys Compd. 726 (2017) 885-895. https://doi.org/10.1016/j.jallcom.2017.08.067.

[14] W.R. Wang, W.L. Wang, S.C. Wang, Y.C. Tsai, C.H. Lai, J.W. Yeh, Effects of $\mathrm{Al}$ addition on the microstructure and mechanical property of $\mathrm{Al} \times \mathrm{CoCrFeNi}$ high-entropy alloys, Intermetallics. 26 (2012) 44-51. https://doi.org/10.1016/j.intermet.2012.03.005.

[15] G.J. Zhang, Q.W. Tian, K.X. Yin, S.Q. Niu, M.H. Wu, W.W. Wang, Y.N. Wang, J.C. Huang, Effect of Fe on microstructure and properties of 
$\mathrm{AlCoCrFexNi}(\mathrm{x}=1.5,2.5)$ high entropy alloy coatings prepared by laser cladding, Intermetallics. 119 (2020). https://doi.org/10.1016/j.intermet.2020.106722.

[16] M. Zhang, L. Zhang, J. Fan, G. Li, P.K. Liaw, R. Liu, Microstructure and enhanced mechanical behavior of the A17Co24Cr21Fe24Ni24 high-entropy alloy system by tuning the Cr content, Mater. Sci. Eng. A. 733 (2018) 299-306. https://doi.org/10.1016/j.msea.2018.07.069.

[17] Y. Zhao, H. Cui, M. Wang, Y. Zhao, X. Zhang, C. Wang, The microstructures and properties changes induced by $\mathrm{Al}$ :Co ratios of the $\mathrm{AlXCrCo} 2-\mathrm{XFeNi}$ high entropy alloys, Mater. Sci. Eng. A. 733 (2018) 153-163. https://doi.org/10.1016/j.msea.2018.07.045.

[18] G. Qin, W. Xue, C. Fan, R. Chen, L. Wang, Y. Su, H. Ding, J. Guo, Effect of Co content on phase formation and mechanical properties of (AlCoCrFeNi)100-xCox high-entropy alloys, Mater. Sci. Eng. A. 710 (2018) 200-205. https://doi.org/10.1016/j.msea.2017.10.088.

[19] H. Liu, J. Liu, X. Li, P. Chen, H. Yang, J. Hao, Effect of heat treatment on phase stability and wear behavior of laser clad AlCoCrFeNiTi0.8 high-entropy alloy coatings, Surf. Coatings Technol. 392 (2020). https://doi.org/10.1016/j.surfcoat.2020.125758.

[20] H. Liu, T. Zhang, S. Sun, G. Zhang, X. Tian, P. Chen, Microstructure and dislocation density of $\mathrm{AlCoCrFeNiSix} \mathrm{high} \mathrm{entropy} \mathrm{alloy} \mathrm{coatings} \mathrm{by} \mathrm{laser}$ cladding, Mater. Lett. 283 (2021) 128746. https://doi.org/10.1016/j.matlet.2020.128746.

[21] Z. Cai, G. Jin, X. Cui, Z. Liu, W. Zheng, Y. Li, L. Wang, Synthesis and microstructure characterization of $\mathrm{Ni}-\mathrm{Cr}-\mathrm{Co}-\mathrm{Ti}-\mathrm{V}-\mathrm{Al}$ high entropy alloy coating on Ti-6Al-4V substrate by laser surface alloying, Mater. Charact. 120 (2016) 229-233. https://doi.org/10.1016/j.matchar.2016.09.011.

[22] Y. Lv, R. Hu, Z. Yao, J. Chen, D. Xu, Y. Liu, X. Fan, Cooling rate effect on microstructure and mechanical properties of AlxCoCrFeNi high entropy alloys, Mater. Des. 132 (2017) 392-399. https://doi.org/10.1016/j.matdes.2017.07.008. 
[23] Z.Y. Zhou, X.B. Liu, S.G. Zhuang, X.H. Yang, M. Wang, C.F. Sun, Preparation and high temperature tribological properties of laser in-situ synthesized self-lubricating composite coatings containing metal sulfides on Ti6Al4V alloy, Appl. Surf. Sci. 481 (2019) 209-218. https://doi.org/10.1016/j.apsusc.2019.03.092.

[24] S. Praveen, B.S. Murty, R.S. Kottada, Alloying behavior in multi-component $\mathrm{AlCoCrCuFe}$ and $\mathrm{NiCoCrCuFe}$ high entropy alloys, Mater. Sci. Eng. A. 534 (2012) 83-89. https://doi.org/10.1016/j.msea.2011.11.044.

[25] Y.F. Ye, Y.H. Zhang, Q.F. He, Y. Zhuang, S. Wang, S.Q. Shi, A. Hu, J. Fan, Y. Yang, Atomic-scale distorted lattice in chemically disordered equimolar complex alloys, Acta Mater. 150 (2018) 182-194. https://doi.org/10.1016/j.actamat.2018.03.008.

[26] T. Yang, Y.L. Zhao, Y. Tong, Z.B. Jiao, J. Wei, J.X. Cai, X.D. Han, D. Chen, A. Hu, J.J. Kai, K. Lu, Y. Liu, C.T. Liu, Multicomponent intermetallic nanoparticles and superb mechanical behaviors of complex alloys, Science (80-. ). 362 (2018) 933-937. https://doi.org/10.1126/science.aas8815.

[27] J.Y. He, W.H. Liu, H. Wang, Y. Wu, X.J. Liu, T.G. Nieh, Z.P. Lu, Effects of $\mathrm{Al}$ addition on structural evolution and tensile properties of the $\mathrm{FeCoNiCrMn}$ high-entropy alloy system, Acta Mater. 62 (2014) 105-113. https://doi.org/10.1016/j.actamat.2013.09.037.

[28] W. Cui, S. Karnati, X. Zhang, E. Burns, F. Liou, Fabrication of AlCoCrFeNi high-entropy alloy coating on an AISI 304 substrate via a CoFe2Ni intermediate layer, Entropy. 21 (2019). https://doi.org/10.3390/e21010002.

[29] K.R. Lim, H.J. Kwon, J.H. Kang, J.W. Won, Y.S. Na, A novel ultra-high-strength duplex $\mathrm{Al}-\mathrm{Co}-\mathrm{Cr}-\mathrm{Fe}-\mathrm{Ni}$ high-entropy alloy reinforced with body-centered-cubic ordered-phase particles, Mater. Sci. Eng. A. 771 (2020) 138638. https://doi.org/10.1016/j.msea.2019.138638.

[30] G. Qin, W. Xue, R. Chen, H. Zheng, L. Wang, Y. Su, H. Ding, J. Guo, H. Fu, Grain refinement and FCC phase formation in AlCoCrFeNi high entropy alloys by the addition of carbon, Materialia. 6 (2019) 100259. 
https://doi.org/10.1016/j.mtla.2019.100259.

[31] V. Soni, B. Gwalani, T. Alam, S. Dasari, Y. Zheng, O.N. Senkov, D. Miracle, R. Banerjee, Phase inversion in a two-phase, $\mathrm{BCC}+\mathrm{B} 2$, refractory high entropy alloy, Acta Mater. 185 (2020) 89-97. https://doi.org/10.1016/j.actamat.2019.12.004.

[32] H. Qiu, H. Zhu, J. Zhang, Z. Xie, Effect of Fe content upon the microstructures and mechanical properties of FexCoNiCu high entropy alloys, Mater. Sci. Eng. A. 769 (2020) 138514. https://doi.org/10.1016/j.msea.2019.138514.

[33] W. Yuan, R. Li, Z. Chen, J. Gu, Y. Tian, A comparative study on microstructure and properties of traditional laser cladding and high-speed laser cladding of Ni45 alloy coatings, Surf. Coatings Technol. (2020) 126582. https://doi.org/10.1016/j.surfcoat.2020.126582.

[34] H. zheng Wang, Y. hai Cheng, X. cheng Zhang, J. yong Yang, C. ming Cao, Effect of laser scanning speed on microstructure and properties of Fe based amorphous/ nanocrystalline cladding coatings, Mater. Chem. Phys. 250 (2020) 123091. https://doi.org/10.1016/j.matchemphys.2020.123091.

[35] H. Wang, W. Zhang, Y. Peng, M. Zhang, S. Liu, FeCoCrNi-Mo High Entropy Alloy / Diamond Composite Coatings by High Speed Laser Cladding, Coatings. (2020).

[36] H. Shiratori, T. Fujieda, K. Yamanaka, Y. Koizumi, K. Kuwabara, T. Kato, A. Chiba, Relationship between the microstructure and mechanical properties of an equiatomic $\mathrm{AlCoCrFeNi}$ high-entropy alloy fabricated by selective electron beam melting, Mater. Sci. Eng. A. 656 (2016) 39-46. https://doi.org/10.1016/j.msea.2016.01.019.

[37] Y. Sun, P. Chen, L. Liu, M. Yan, X. Wu, C. Yu, Z. Liu, Local mechanical properties of AlxCoCrCuFeNi high entropy alloy characterized using nanoindentation, Intermetallics. 93 (2018) 85-88. https://doi.org/10.1016/j.intermet.2017.11.010.

[38] Y. V. Milman, A.A. Golubenko, S.N. Dub, Indentation size effect in nanohardness, Acta Mater. 59 (2011) 7480-7487. 
https://doi.org/10.1016/j.actamat.2011.08.027.

[39] W.C. Oliver, G.M. Pharr, I. Introduction, An improved technique for determining hardness and elastic modulus using load and displacement sensing indentation experiments, Mater. Res. Soc. 7 (1992) 1564-1583.

[40] G. Muthupandi, K.R. Lim, Y.S. Na, J. Park, D. Lee, H. Kim, S. Park, Y.S. Choi, Pile-up and sink-in nanoindentation behaviors in $\mathrm{AlCoCrFeNi}$ multi-phase high entropy alloy, Mater. Sci. Eng. A. 696 (2017) 146-154. https://doi.org/10.1016/j.msea.2017.04.045.

[41] M. Li, J. Gazquez, A. Borisevich, R. Mishra, K.M. Flores, Evaluation of microstructure and mechanical property variations in $\mathrm{AlxCoCrFeNi} \mathrm{high}$ entropy alloys produced by a high-throughput laser deposition method, Intermetallics. 95 (2018) 110-118. https://doi.org/10.1016/j.intermet.2018.01.021.

[42] Z. Tang, O.N. Senkov, C.M. Parish, C. Zhang, F. Zhang, L.J. Santodonato, G. Wang, G. Zhao, F. Yang, P.K. Liaw, Tensile ductility of an AlCoCrFeNi multi-phase high-entropy alloy through hot isostatic pressing (HIP) and homogenization, Mater. Sci. Eng. A. 647 (2015) 229-240. https://doi.org/10.1016/j.msea.2015.08.078.

[43] M. Zhang, L. Zhang, J. Fan, P. Yu, G. Li, Anomalous microstructure and excellent mechanical behaviors of ( $\mathrm{CoCrFeNi}$ ) 6-x-y $\mathrm{Cr} x \mathrm{Al}$ y high-entropy alloy induced by $\mathrm{Cr}$ and $\mathrm{Al}$ addition, Mater. Sci. Eng. A. 752 (2019) 63-74. https://doi.org/10.1016/j.msea.2019.02.071.

[44] A. Leyland, A. Matthews, On the significance of the $\mathrm{H} / \mathrm{E}$ ratio in wear control: A nanocomposite coating approach to optimised tribological behaviour, Wear. 246 (2000) 1-11. https://doi.org/10.1016/S0043-1648(00)00488-9.

[45] P. Zhang, M. Li, H. Yan, J. Chen, Z. Yu, X. Ye, Microstructure evolution of $\mathrm{Ni}-\mathrm{Mo}-\mathrm{Fe}-\mathrm{Si}$ quaternary metal silicide alloy composite coatings by laser cladding on pure Ni, J. Alloys Compd. 785 (2019) 984-1000. https://doi.org/10.1016/j.jallcom.2019.01.191.

[46] R. Zhu, P. Zhang, Z. Yu, H. Yan, S. Li, D. Wu, H. Shi, Surface \& Coatings 
Technology Microstructure and wide temperature range self-lubricating properties of laser cladding NiCrAlY / Ag 2 O / Ta 2 O 5 composite coating, 383 (2020). https://doi.org/10.1016/j.surfcoat.2019.125248.

[47] L. Chen, K. Bobzin, Z. Zhou, L. Zhao, M. Öte, T. Königstein, Z. Tan, D. He, Wear behavior of HVOF-sprayed Al0.6TiCrFeCoNi high entropy alloy coatings at different temperatures, Surf. Coatings Technol. 358 (2019) 215-222. https://doi.org/10.1016/j.surfcoat.2018.11.052.

[48] X. Yang, Y. Zhang, Prediction of high-entropy stabilized solid-solution in multi-component alloys, Mater. Chem. Phys. 132 (2012) 233-238. https://doi.org/10.1016/j.matchemphys.2011.11.021.

[49] Y.F. Juan, J. Li, Y.Q. Jiang, W.L. Jia, Z.J. Lu, Modified criterions for phase prediction in the multi-component laser-clad coatings and investigations into microstructural evolution/wear resistance of FeCrCoNiAlMox laser-clad coatings, Appl. Surf. Sci. 465 (2019) 700-714. https://doi.org/10.1016/j.apsusc.2018.08.264.

[50] S. Guo, C. Ng, J. Lu, C.T. Liu, Effect of valence electron concentration on stability of fcc or bcc phase in high entropy alloys, J. Appl. Phys. 109 (2011). https://doi.org/10.1063/1.3587228.

[51] M. Dada, P. Popoola, N. Mathe, S. Pityana, S. Adeosun, Effect of laser parameters on the properties of high entropy alloys: A preliminary study, Mater. Today Proc. (2020). https://doi.org/10.1016/j.matpr.2020.04.198.

[52] R. Wang, K. Zhang, C. Davies, X. Wu, Evolution of microstructure, mechanical and corrosion properties of $\mathrm{AlCoCrFeNi}$ high-entropy alloy prepared by direct laser fabrication, J. Alloys Compd. 694 (2017) 971-981. https://doi.org/10.1016/j.jallcom.2016.10.138.

[53] P. Zhang, M. Li, Z. Yu, Microstructures evolution and micromechanics features of Ni-Cr-Si coatings deposited on copper by laser cladding, Materials (Basel). 11 (2018). https://doi.org/10.3390/ma11060875.

[54] M. Schwarz, C.B. Arnold, M.J. Aziz, D.M. Herlach, Dendritic growth velocity and diffusive speed in solidification of undercooled dilute Ni-Zr melts, Mater. 
Sci. Eng. A. 226-228 (1997) 420-424.

https://doi.org/10.1016/s0921-5093(96)10656-0.

[55] D. Wang, C. Song, Y. Yang, Y. Bai, Investigation of crystal growth mechanism during selective laser melting and mechanical property characterization of 316L stainless steel parts, Mater. Des. 100 (2016) 291-299. https://doi.org/10.1016/j.matdes.2016.03.111.

[56] T. Suzuki, Fundamentals of solidification phenomena, Keikinzoku/Journal Japan Inst. Light Met. 46 (1996) 156-161.

[57] J. Cheng, Y. Feng, C. Yan, X. Hu, R. Li, X. Liang, Development and Characterization of Al-Based Amorphous Coating, Jom. 72 (2020) 745-753. https://doi.org/10.1007/s11837-019-03966-y.

[58] R. Li, M. Wang, Z. Li, P. Cao, T. Yuan, H. Zhu, Developing a high-strength Al-Mg-Si-Sc-Zr alloy for selective laser melting: Crack-inhibiting and multiple strengthening mechanisms, Acta Mater. 193 (2020) 83-98. https://doi.org/10.1016/j.actamat.2020.03.060. 


\section{Declaration of interests}

$\bigotimes$ The authors declare that they have no known competing financial interests or personal relationships that could have appeared to influence the work reported in this paper.

$\square$ The authors declare the following financial interests/personal relationships which may be considered as potential competing interests:

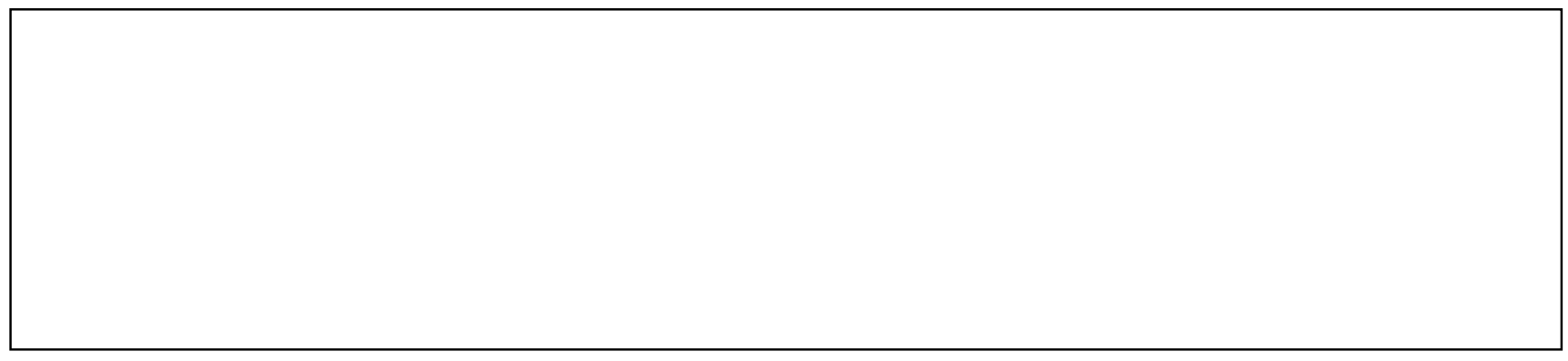

